\title{
Effect of Excipients on Recombinant Interleukin-2 Stability in Aqueous Buffers
}

\author{
A. S. Prakasha Gowda* (i), Andrew D. Schaefer, Terry K. Schuck \\ Department of Raw Materials, Eurofins BioPharma Product Testing, Lancaster, USA \\ Email: ^PrakashagowdaAladahalliSanneGowda@eurofinsus.com
}

How to cite this paper: Gowda, A.S.P., Schaefer, A.D. and Schuck, T.K. (2021) Effect of Excipients on Recombinant Interleukin-2 Stability in Aqueous Buffers. American Journal of Analytical Chemistry, 12, 347-372. https://doi.org/10.4236/ajac.2021.1210022

Received: September 21, 2021

Accepted: October 26, 2021

Published: October 29, 2021

Copyright $\odot 2021$ by author(s) and Scientific Research Publishing Inc. This work is licensed under the Creative Commons Attribution International License (CC BY 4.0).

http://creativecommons.org/licenses/by/4.0/

(c) (i) Open Access

\begin{abstract}
In order to retain structural and functional integrity, protein medicines are frequently stabilized with excipients in aqueous solutions. The goal of this investigation was to see how stable IL-2 is with excipients that are acceptable for cell therapy. We investigated the time-dependent stability of commercially available recombinant IL-2 in aqueous solutions (CTS, RPMI, PBS, and water) at different temperatures $\left[2^{\circ} \mathrm{C}-8^{\circ} \mathrm{C}\right.$, room temperature $\left(20^{\circ} \mathrm{C} \pm 2^{\circ} \mathrm{C}\right)$ and $37^{\circ} \mathrm{C}$ ] in the presence of excipients (EDTA, methionine, histidine, and glycine) over a period of up to 30 days. To detect and quantify IL-2, reversed phase high performance liquid chromatography was employed. Electrophoresis on a sodium dodecyl sulfate polyacrylamide gel was used to assess conformational stability. We discovered that IL-2 stability was improved in aqueous solutions including excipients, and that it may have retained its biological activity and sterility in these conditions.
\end{abstract}

\section{Keywords}

Interleukin-2, Excipients, Stability, RP-HPLC, SDS-PAGE

\section{Introduction}

The glycoprotein human interleukin-2 (IL-2) is generated and released by activated $\mathrm{T}$ cells [1] and is required for $\mathrm{T}$ and $\mathrm{B}$ lymphocyte proliferation. The cytokine interleukin-2 (IL-2) has been used to treat metastatic renal cell carcinoma and metastatic melanoma [2]. It has been cloned and its coding gene is being expressed [3]. The mature protein has three cysteine residues, two of which form a disulfide link that is required for its biological function [4]. Its activity is not dependent on the action of the third cysteine residue [5].

Recombinant IL-2 (Aldesleukin) is frequently used alternatively of natural ${ }^{\star}$ Corresponding author. 
IL-2. Aldesleukin is no longer glycosylated because it is made from Escherichia coli (E. coli). It lacks an N-terminal alanine due to the fact the codon for this amino acid used to be eliminated all through the genetic engineering process, and serine changed through cysteine at amino acid position 125 . Hydrophobicity is considered to be a characteristic of interleukins. Recombinant IL-2 is susceptible to aggregation due to its hydrophobicity. We chosen and examined the stability of this commercially available recombinant human IL-2. Protein structure and feature are distinct, necessitating positive situations for the protein to conform, stable, and function correctly. When a protein's natural environment modifications unexpectedly or it is exposed to adverse conditions, it degrades, denatures, or precipitates, generally with long-term effects. Depending on its experimental utilization and protein properties, protein solutions might also require the addition of excipients to extend their steadiness and shelf life. Excipients are regularly required to preserve protein structure and function in watery environments.

As a result, most studies on IL-2 stability during lyophilization [6] [7] focus on stress generated by heat and dehydration conditions, rather than interfacial alterations [8]. In the presence of anti-oxidants [9] and surfactants [10] as well as external variables like $\mathrm{pH}$ and temperature, the stability of IL-2 has been tested in aqueous conditions [11]. A prior study looked at protein precipitation and loss during the refolding, storage, or transport of IL-2 [12]. IL-2 formulations that are solid freeze-dried have been proven to be more stable than their liquid counterparts [13]. The chemical breakdown of cytokines is mediated by oxidation [10]. While there are several oxidation-sensitive residues in IL-2 (methionine, tryptophan, histidine, and tyrosine), methionine residue 104 is the easiest to oxidize [14]. In the presence of reducing chemicals or during long-term storage, the methionine residue undergoes oxidation [9]. Antioxidants like EDTA and methionine aid in the preservation of IL-2 against oxidation [10]. Protein treatments have generally been administered as aqueous injectable solutions due to bioavailability concerns with alternative modes of administration. Liquid solutions, on the other hand, are easier to process, handle, and apply.

Because of the issues with IL-2 stability, new remedy techniques that maintain the protein functional are truly needed. Not solely are such options necessary for the storage and transportation of IL-2, however they are additionally required to support new IL-2 administration directions. It is but uncertain how stable IL-2 is in cell remedy settings. This research is interested in the use of IL-2 as a supplement in cell culture treatment medium for T cell activation, as well as a practical method for assessing IL-2 stability in that medium. The goal of this work was to see how antioxidants (EDTA and methionine) and amino acids (histidine and glycine) affected IL-2 stability in aqueous solutions at different temperatures. The samples had been evaluated the use of reversed phase high-performance liquid chromatography, with sodium dodecyl sulfate polyacrylamide gel electrophoresis as a secondary stability indicator. 


\section{Experimental}

\subsection{Materials}

Recombinant interleukin-2 (Aldesleukin) was purchased from PeproTech (Rocky Hill, NJ, USA) and reconstituted in milli-Q water. Ethylenediaminetetraacetic acid (EDTA) was purchased from Sigma Aldrich (St Louis, MO, USA) and dissolved in milli-Q water. The Histidine monohydrate, Glycine hydrogen chloride, and L-methionine were purchased from Sigma Aldrich in St Louis, MO, USA, and dissolved each in milli-Q water. Acetonitrile was received from Fisher Scientific (Fair Lawn, NJ, USA), Trifluoroacetic Acid, HPLC Grade was purchased from Sigma Aldrich (Burlington, MA, USA), Acetic acid, HPLC grade was purchased from EMD Millipore corporation (Billerica, MA, USA), $12 \times 32 \mathrm{~mm}$ glass screw neck vial quick thread, LectraBond cap preslit PTFE/silicone septa was purchased from Waters (USA). 10× Tris-glycine SDS running buffer, simply blue safe stain, $2 \times$ sample buffer, SeeBlue Plus2 pre-Stained Standard and $4 \%-20 \%$ gradient gels were purchased from Life Technologies (Carlsbad, CA, USA). Phosphate buffer saline and Cell Therapy Systems OpTimizer medium were purchased from Life Technologies Corporation (Grand Island, NY, USA). Roswell Park Memorial Institute 1640 medium was purchased from Life Technologies Limited (Paisley, PA4 9RF, UK). Milli-Q water for solutions made in house with a Milli-Q system (Millipore, Milford, MA, USA). All other chemicals were obtained in an analytical grade or from standard commercial suppliers.

\subsection{IL-2 Compatibility with Glass Vials}

Surface adsorption is a concern for hydrophobic proteins like IL-2 since they are frequently employed in small amounts, resulting in lower protein concentration in the final product. The most commonly used processing and storage materials, glass and plastics, are well-known for adsorbing large amounts of protein [15]. This can result in protein loss, particularly in low-concentrated protein solutions where the percentage loss is high. IL-2 was diluted to $0.018 \mathrm{mg} / \mathrm{mL}$ in a solution of $10 \mathrm{mM}$ sodium citrate and $0.1 \mathrm{~N}$ acetic acid, $\mathrm{pH} 3.0$, and placed in glass screw neck vials to study adsorption. Each vial was sealed with a LectraBond cap and kept sealed for 0,24 , and 96 hours at $2^{\circ} \mathrm{C}-8^{\circ} \mathrm{C}$. To see if IL- 2 could be utilized in glass vials, the solutions were injected individually and the peak areas of the freshly created IL-2 solutions were compared.

\subsection{Selection of Aqueous Solutions for IL-2 Stability}

IL-2, a key cytokine for $\mathrm{T}$ cell activation, is frequently incorporated in or required by a variety of formulations. Researchers can choose from a variety of commercially available $\mathrm{T}$ cell culture medium options, including all-in-one comprehensive formulations. The majority of cell culture media lack a components list, and the type of media chosen by a researcher is frequently dictated by the application. While Roswell Park Memorial Institute 1640 (RPMI) is the most often used medium for cultivating $\mathrm{T}$ cells in research, full formulations like Cell 
Therapy Systems (CTS) OpTimizer are becoming more popular [16]. Phosphate buffer saline (PBS) is a balanced $\mathrm{pH}$ salt solution that reduces protein adsorption [17] and is often used in cell culture for washing and diluting cells. Water is another of them, and it's widely employed for dilution or temporary storage of biomolecules or reagents.

\subsection{Chromatographic Conditions and Instrumentation}

The reverse phase high-performance liquid chromatography (RP-HPLC) was performed [18] with a Agilent 1100 series, comprised of a quaternary pump solvent delivery module, online degasser, thermostated column compartment, auto sampler, auto injector with $100 \mu \mathrm{L}$ injection loop, and a Variable Wavelength Detector. Samples were maintained at $5^{\circ} \mathrm{C}$ in the autosampler prior to analysis. The system was used in a room temperature (RT) HPLC laboratory $\left(20^{\circ} \mathrm{C} \pm\right.$ $2^{\circ} \mathrm{C}$ ). The analysis was performed on a ZORBAX $300 \mathrm{SB}-\mathrm{CN}, 150 \times 4.6 \mathrm{~mm}, 3.5$ $\mu \mathrm{m}$ column, and column temperature was maintained at $30^{\circ} \mathrm{C}$ during analysis. The mobile phase A contained $0.1 \%$ trifluoroacetic acid (TFA) in water and $\mathrm{B}$ $0.1 \%$ TFA in acetonitrile. Gradient elution was used, and the program was set as follows: $30 \%-80 \% \mathrm{~B}$ from 0 to $10 \mathrm{~min}$; $80 \%-100 \% \mathrm{~B}$ from 10 to $12 \mathrm{~min}$ and $30 \%$ B from 13 - 20 min. Injection volume was kept constant $50 \mu \mathrm{L}$. The flow rate of the mobile phase was set at $0.8 \mathrm{~mL} / \mathrm{min}$ and the eluate was monitored at an UV wavelength of $214 \mathrm{~nm}$. Chromatogram output, integration of peaks, calculation of peak areas and retention times were obtained using the Empower software, version 3 .

\subsection{Effect of Excipients on IL-2 Stability in Aqueous Solutions}

To test the effect of antioxidants and amino acids on IL-2 stability, IL-2 was diluted to approximately $0.018 \mathrm{mg} / \mathrm{mL}$ in CTS, RPMI, PBS, and water in the presence of $1 \mathrm{mg} / \mathrm{mL}$ EDTA, $5 \mathrm{mg} / \mathrm{mL}$ methionine (Met), $5 \mathrm{mg} / \mathrm{mL}$ histidine (His), and $5 \mathrm{mg} / \mathrm{mL}$ glycine (Gly) in separate glass vials. For short-term stability, each sample vial was incubated at $37^{\circ} \mathrm{C}$ for $0,1,2,3,4$, and 5 days. For up to 30 days, solutions were incubated at $2^{\circ} \mathrm{C}-8^{\circ} \mathrm{C}$, RT $\left(20^{\circ} \mathrm{C} \pm 2^{\circ} \mathrm{C}\right)$, and $37^{\circ} \mathrm{C}$ to test their long-term stability. The percent recovery of IL-2 was calculated using linear regression of the analytical standard curve after each solution was evaluated individually using RP-HPLC. The results of the IL-2 assay were compared to samples that had been newly prepared and were free of excipients.

\subsection{Sodium Dodecyl Sulphate Polyacrylamide Gel Electrophoresis (SDS-PAGE) Analysis}

To learn more, $1 \mu \mathrm{g}$ of IL-2 was prepared in CTS, RPMI, PBS, and water in separate vials with $1 \mathrm{mg} / \mathrm{mL}$ EDTA, $5 \mathrm{mg} / \mathrm{mL}$ Met, $5 \mathrm{mg} / \mathrm{mL}$ His, and $5 \mathrm{mg} / \mathrm{mL}$ Gly. To ensure short-term stability, all vials were incubated at $37^{\circ} \mathrm{C}$ for $0,1,2,3,4$, and 5 days. For up to 30 days, solutions were incubated at $2^{\circ} \mathrm{C}-8^{\circ} \mathrm{C}$, RT $\left(20^{\circ} \mathrm{C} \pm\right.$ $2^{\circ} \mathrm{C}$ ) and $37^{\circ} \mathrm{C}$ to determine long-term stability. Periodically, the solutions were examined by SDS-PAGE under reduced conditions using $4 \%-20 \%$ tris-glycine 
SDS gradient gels, as described by Laemmli [19]. Before being put onto the gel for examination, samples of IL-2 stability were first treated in the sample buffer at $95^{\circ} \mathrm{C}$ for 10 minutes. SeeBlue Plus2 pre-Stained Standard was used as the protein standard, and it was not further processed. Gels were run at RT in tris-glycine SDS buffer at a constant voltage $(200 \mathrm{~V})$ until the dye front reached the end of the gel. SDS-PAGE gels were dyed using SimpllyBlueTM Safe Stain, washed twice in Milli- $\mathrm{Q}$ water, and then destained twice in Milli-Q water. The gels were imaged using a densitometer.

\section{Results}

The goal of these tests was to find an excipient that could keep IL-2 stable in a wide range of aqueous solutions utilized in cell therapy. The influence of antioxidants and amino acids on the aqueous stability of IL-2 was examined in order to select an appropriate excipient for stability studies.

\subsection{Optimization of RP-HPLC Analytical Conditions}

The RP-HPLC analytical conditions for separating and quantifying IL-2 in aqueous solutions (CTS, RPMI, PBS, and water) were investigated for their stability. The physicochemical properties and chromatographic behaviors of IL-2 were studied in the literature. Additionally, as per our previous analytical conditions [18], the impacts of a specific combination of column type, mobile phase composition, and detection system were studied. The maximum injection volume for future applications in biological sample analysis was set at $50 \mu \mathrm{L}$. The analysis was limited to 20 minutes, and the flow rate was set to $0.8 \mathrm{~mL} / \mathrm{min}$ to sharpen the peak, resulting in an IL-2 retention time of 7.2 minutes. This flow rate was found to be the best for reducing total run time while maintaining acceptable column backpressure. To ensure that all of the components in the sample solution were sufficiently separated, the column temperature was kept at $30^{\circ} \mathrm{C}$ The detection wavelength of $214 \mathrm{~nm}$ was investigated for IL-2 while determining the detection wavelength for the analytical procedure, and it was found to yield peaks that were extremely sensitive and reproducible. IL-2 separated well in 10 minutes in this final optimized RP-HPLC condition, followed by a re-equilibration to the original condition.

The selectivity of a chromatographic device refers to its capability to chemically distinguish between pattern components. Chromatograms from $0.1 \mathrm{~N}$ acetic acid, CTS, RPMI, PBS, and water were compared to those with IL-2 present to better understand the aqueous solutions matrix impact. For this study, $50 \mu \mathrm{L}$ of each aqueous solution (without and with IL-2) were introduced into the HPLC apparatus individually. IL-2 eluted as a single peak under the specified chromatographic conditions. As shown by peak purity analysis, there seem to be no co-eluting peaks during the IL-2 retention time that could interfere with the peak of interest, implying that the IL-2 peak is pure. The chromatogram results are shown in Figure 1. 

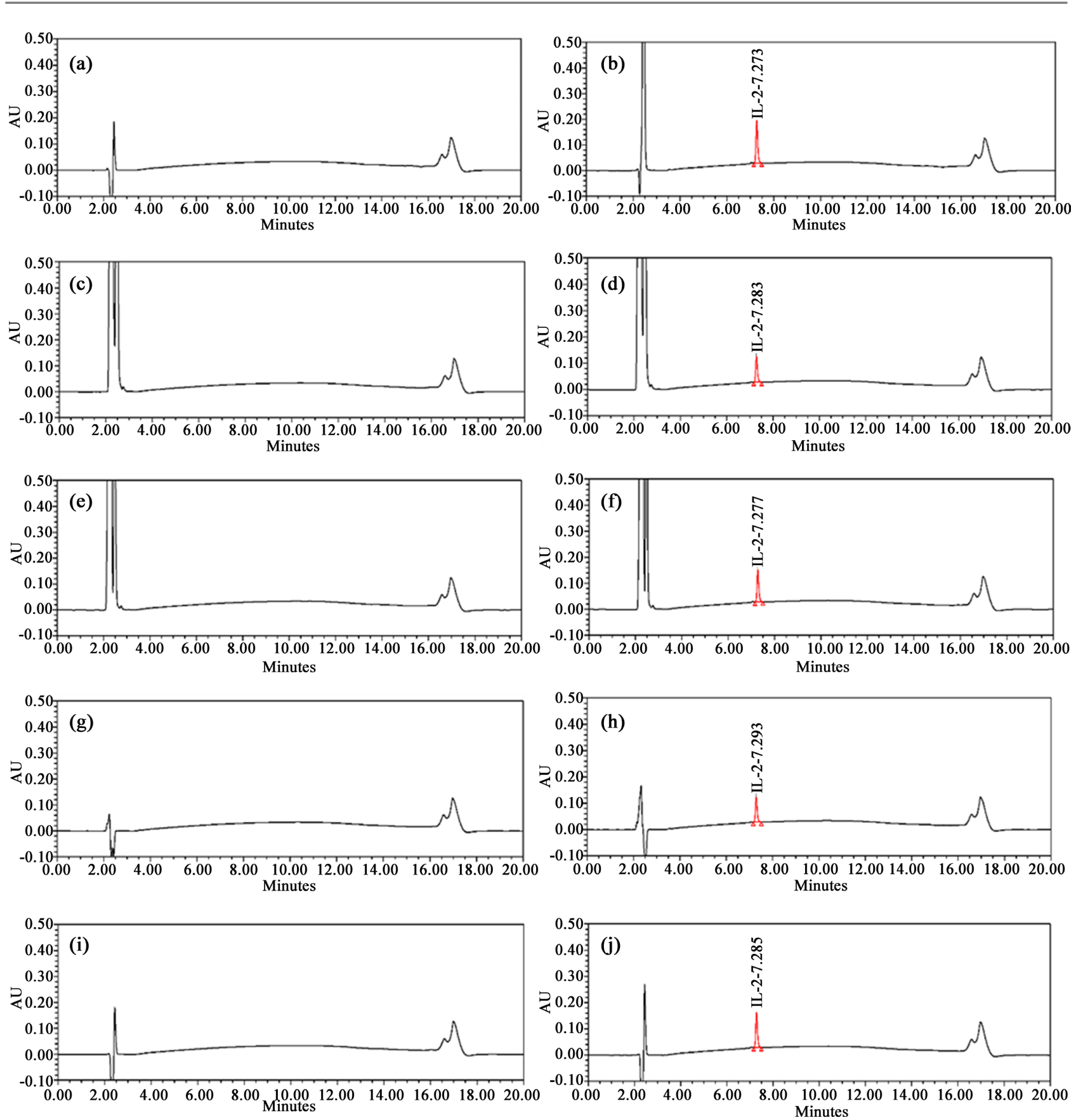

Figure 1. Effect of aqueous solutions matrix on chromatography separation. Fifty $\mu$ l of aqueous solutions were injected into the HPLC system separately. (a) $0.1 \mathrm{~N}$ acetic acid, (b) IL-2 in 0.1 acetic acid (c) CTS, (d) IL-2 in CTS, (e) RPMI, (f) IL-2 in RPMI (g) PBS, (h) IL-2 in PBS, (i) water and (j) IL-2 in water. The result of the chromatograms shows that the peak of analyte was pure, and there are no co-eluting peaks at the retention time of the IL-2 to interfere with the peak of interest.

\subsection{Linearity Study}

According to our earlier studies [18], the linearity was explored. The capacity of an analytical method to produce test findings that are directly proportional to the analyte concentration within a certain range is known as linearity. The linearity of IL-2 was investigated throughout a range of concentrations from $0.00458 \mathrm{mg} / \mathrm{mL}$ to $0.0495 \mathrm{mg} / \mathrm{mL}$. The calibration graph was created by plotting 
the peak area acquired from the HPLC against corresponding concentrations. A linear regression analysis was used to determine the linearity. The standard curve was created by graphing peak area versus IL-2 concentration. Over the range, the standard curve for IL-2 was linear, and the coefficient of determination $\left(\mathrm{R}^{2}\right)$ for IL-2 was determined to be 1.0. The y-intercept for IL-2 were calculated as a proportion of the analytical concentration response. The equation of the standard curve in this range, $y=20423353.3 x-23$ 086.2, relates the peak area $(\mathrm{Y})$ to the IL-2 concentration (X in $\mathrm{mg} / \mathrm{mL}$ ) (Figure 2 ). When $\mathrm{R}^{2}$ values are more than 0.999, it means that all of the concentrations used have a good linear association.

\subsection{IL-2 Compatibility with Glass Vials}

IL-2 and other proteins can bind to a various surfaces, and changing the $\mathrm{pH}$ can change the degree of adsorption by raising protein charge density, which reduces the hydrophobic effect that causes molecules to congregate or adsorb [13]. This mechanism can significantly alter the secondary structure of IL-2, causing it to lose biological function or become unstable. Adsorption can also be minimized by optimizing the protein solution, adding excipients such as surfactants [15], and adjusting the $\mathrm{pH}$ and ionic strength. The pace of protein adsorption varies depending on the surface material and the protein, although it is normally a relatively fast process [20] [21]. In contrast, we investigated the compatibility of glass vials with IL-2 in aqueous solutions and found that the IL-2 peak area did not significantly differ much. This clearly proved that, in our testing conditions, irreversible adsorption to glass vials does not provide a major risk of losing significant amounts of IL-2. Surfactants, on the other hand, were not necessary to prevent IL-2 from adsorbing in glass vials under the conditions we examined. Table 1 summarizes the recovery of IL-2 at the start, after 24, and after 96 hours of storage at $2^{\circ} \mathrm{C}-8^{\circ} \mathrm{C}$.

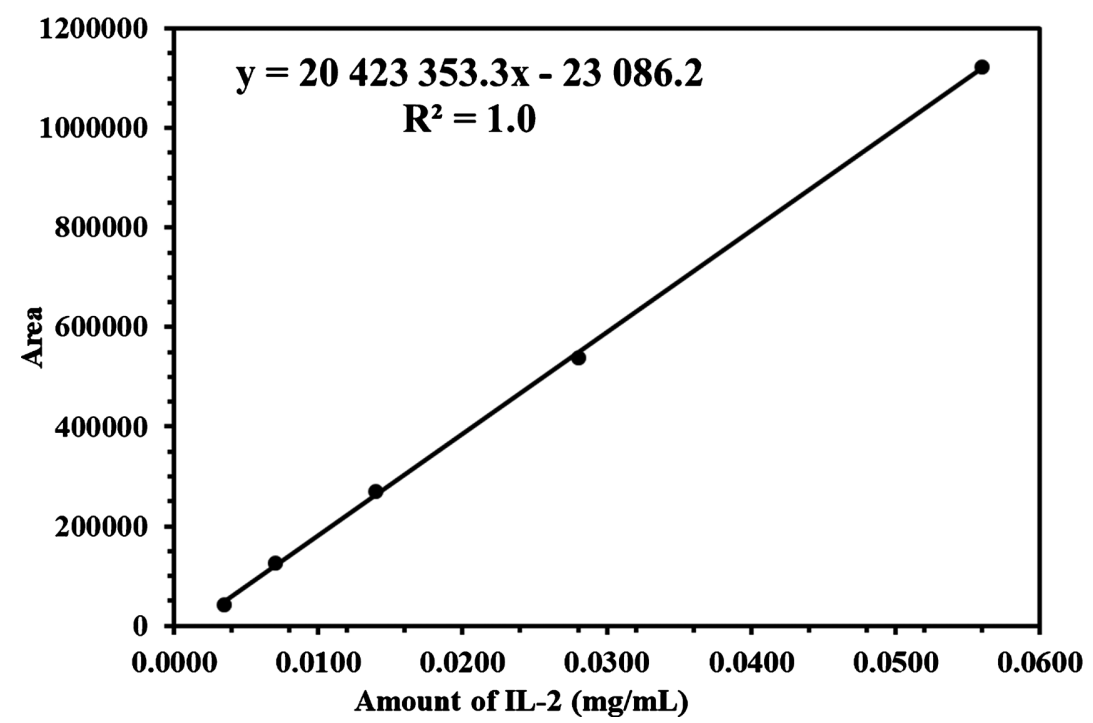

Figure 2. Linearity curve of IL-2. 


\subsection{Effect of Excipients on the Stability of IL-2 in Aqueous Solutions}

The $\mathrm{pH}$, temperature, and components of an aqueous solution can have a considerable impact on the structure of a protein medicine, resulting in poor stability and therapeutic inactivity. To investigate the effect of antioxidants and amino acids on IL-2 stability in aqueous solutions, IL-2 was prepared in CTS, RPMI, PBS, and water in separate glass vials in the presence of antioxidants and amino acids. Sample vials were incubated at $37^{\circ} \mathrm{C}$ for $0,1,2,3$, and 5 days for short-term stability, while IL-2 sample solutions were incubated for 30 days at different temperatures $\left[2^{\circ} \mathrm{C}-8^{\circ} \mathrm{C}\right.$, RT $\left(20^{\circ} \mathrm{C} \pm 2^{\circ} \mathrm{C}\right)$ and $\left.37^{\circ} \mathrm{C}\right]$ for long-term stability. Following the completion of the incubation time, all of the stability samples were evaluated by RP-HPLC in a single batch. Table 2, Table 3 and

Table 1. Compatibility of IL-2 with HPLC glass vials in aqueous solutions: IL-2 solution was prepared in $10 \mathrm{mM}$ sodium citrate, and $0.1 \mathrm{~N}$ acetic acid, $\mathrm{pH} 3.0$ into glass vials. Each vial was sealed with a LectraBond cap and stored at $2^{\circ} \mathrm{C}-8^{\circ} \mathrm{C}$ for 0,24 and $96 \mathrm{~h}$. Periodically the solutions were analyzed separately by RP-HPLC and the percent recovery of IL-2 was determined by using the Empower software, version 3.

\begin{tabular}{cccccc}
\hline Sample & $\begin{array}{c}\mathbf{0 ~ h} \\
(\text { Area })\end{array}$ & $\begin{array}{c}\mathbf{2 4} \mathrm{h} \\
\text { (Area) }\end{array}$ & $\begin{array}{c}\text { \% IL-2 } \\
\text { Recovered }\end{array}$ & $\begin{array}{c}\mathbf{9 6} \mathrm{h} \\
\text { (Area) }\end{array}$ & $\begin{array}{c}\text { \% IL-2 } \\
\text { Recovered }\end{array}$ \\
\hline IL-2 in 10 mM sodium citrate, pH 3.0 & 467,603 & 443,671 & 94.9 & 444,295 & 95.0 \\
IL-2 in 0.1 N acetic acid, pH 3.0 & 452,564 & 443,290 & 98.0 & 441,459 & 97.5 \\
\hline
\end{tabular}

Table 2. Effect of antioxidants and amino acids on IL-2 stability in CTS and RPMI. In separate glass vials, IL-2 solutions were prepared in CTS and RPMI, in the presence of EDTA, Met, His and Gly. Sample vials were incubated at $37^{\circ} \mathrm{C}$ for $0,1,2,3,4$ and 5 days. To investigate the long-term stability, solutions were incubated at $2^{\circ} \mathrm{C}-8^{\circ} \mathrm{C}, \mathrm{RT}\left(20^{\circ} \mathrm{C} \pm 2^{\circ} \mathrm{C}\right)$ and $37^{\circ} \mathrm{C}$ over a period of up to 30 days. Periodically the solutions were analyzed separately by RP-HPLC and the percent recovery of IL-2 was determined by using the Empower software, version 3. Experiments were performed in triplicate.

\begin{tabular}{|c|c|c|c|c|c|c|c|c|}
\hline \multirow{2}{*}{ IL-2 samples } & \multicolumn{6}{|c|}{$\%$ IL-2 Recovered at $37^{\circ} \mathrm{C}$} & \multirow{2}{*}{$\begin{array}{c}\begin{array}{c}\% \mathrm{IL}-2 \\
\text { Recovered }\end{array} \\
\text { at } 2^{\circ} \mathrm{C}-8^{\circ} \mathrm{C} \\
30 \mathrm{Day}\end{array}$} & \multirow{2}{*}{$\begin{array}{c}\begin{array}{c}\% \text { IL-2 } \\
\text { Recovered } \\
\text { at RT }\end{array} \\
30 \text { Day }\end{array}$} \\
\hline & 0 Day & 1 Day & 2 Day & 3 Day & 5 Day & 30 day & & \\
\hline IL-2 in $0.1 \mathrm{~N}$ acetic acid ( $\mathrm{pH} 3.0$ ) & 96 & 87 & 84 & 85 & 85 & 37 & 74 & 73 \\
\hline IL-2 in CTS (pH 7.5) & 45 & 44 & 24 & 26 & 30 & 0 & 16 & 15 \\
\hline IL-2 in CTS $+1 \mathrm{mg} / \mathrm{mL}$ EDTA & 60 & 52 & 56 & 57 & 66 & 2 & 47 & 34 \\
\hline IL-2 in CTS + $5 \mathrm{mg} / \mathrm{mL}$ Met & 80 & 65 & 62 & 57 & 57 & 52 & 46 & 42 \\
\hline IL-2 in CTS $+5 \mathrm{mg} / \mathrm{mL}$ His & 71 & 62 & 54 & 42 & 42 & 0 & 49 & 3 \\
\hline IL-2 in CTS + $5 \mathrm{mg} / \mathrm{mL}$ Gly & 52 & 57 & 52 & 45 & 32 & 0 & 42 & 0 \\
\hline \multicolumn{9}{|l|}{ RPMI media } \\
\hline IL-2 in RPMI (pH 7.95) & 51 & 34 & 34 & 34 & 39 & 0 & 19 & 9 \\
\hline IL-2 in RPMI + 1 mg/mL EDTA & 71 & 59 & 48 & 63 & 73 & 24 & 59 & 28 \\
\hline IL-2 in RPMI $+5 \mathrm{mg} / \mathrm{mL}$ Met & 86 & 73 & 78 & 67 & 68 & 0 & 62 & 38 \\
\hline $\mathrm{IL}-2$ in $\mathrm{RPMI}+5 \mathrm{mg} / \mathrm{mL}$ His & 69 & 67 & 56 & 43 & 52 & 0 & 52 & 0 \\
\hline IL-2 in RPMI + $5 \mathrm{mg} / \mathrm{mL}$ Gly & 53 & 60 & 47 & 41 & 32 & 0 & 0 & 0 \\
\hline
\end{tabular}


Table 3. Effect of antioxidants and amino acids on IL-2 stability in PBS and water. In separate glass vials, IL-2 solutions were prepared in PBS and water, in the presence of EDTA, Met, His and Gly. Sample vials were incubated at $37^{\circ} \mathrm{C}$ for $0,1,2,3,4$ and 5 days. To investigate the long-term stability, solutions were incubated at $2^{\circ} \mathrm{C}-8^{\circ} \mathrm{C}$, RT $\left(20^{\circ} \mathrm{C} \pm 2^{\circ} \mathrm{C}\right)$ and $37^{\circ} \mathrm{C}$ over a period of up to 30 days. Periodically the solutions were analyzed separately by RP-HPLC and the percent recovery of IL-2 was determined by using the Empower software, version 3. Experiments were performed in triplicate.

\begin{tabular}{|c|c|c|c|c|c|c|c|c|}
\hline \multirow{2}{*}{ IL-2 samples } & \multicolumn{6}{|c|}{$\%$ IL-2 Recovered at $37^{\circ} \mathrm{C}$} & \multirow{2}{*}{$\begin{array}{c}\% \text { IL-2 } \\
\text { Recovered } \\
\text { at } 2^{\circ} \mathrm{C}-8^{\circ} \mathrm{C} \\
30 \text { Day }\end{array}$} & \multirow{2}{*}{$\begin{array}{c}\begin{array}{c}\% \text { IL-2 } \\
\text { Recovered } \\
\text { at RT }\end{array} \\
30 \text { Day }\end{array}$} \\
\hline & 0 Day & 1 Day & 2 Day & 3 Day & 5 Day & 30 Day & & \\
\hline IL-2 in $0.1 \mathrm{~N}$ acetic acid ( $\mathrm{pH} 2.9)$ & 96 & 87 & 84 & 85 & 85 & 37 & 74 & 73 \\
\hline IL-2 in PBS (pH 7.2) & 52 & 37 & 38 & 40 & 51 & 0 & 22 & 24 \\
\hline IL-2 in PBS $+1 \mathrm{mg} / \mathrm{mL}$ EDTA & 74 & 65 & 68 & 77 & 66 & 39 & 55 & 31 \\
\hline $\mathrm{IL}-2$ in PBS $+5 \mathrm{mg} / \mathrm{mL}$ Met & 65 & 26 & 19 & 23 & 18 & 0 & 35 & 20 \\
\hline IL-2 in PBS $+5 \mathrm{mg} / \mathrm{mL}$ His & 28 & 29 & 13 & 25 & 25 & 0 & 0 & 7 \\
\hline IL-2 in PBS $+5 \mathrm{mg} / \mathrm{mL}$ Gly & 18 & 23 & 11 & 23 & 18 & 0 & 0 & 0 \\
\hline \multicolumn{9}{|l|}{ Water } \\
\hline IL-2 in water $(\mathrm{pH} \sim 7.0)$ & 68 & 51 & 44 & 42 & 27 & 6 & 38 & 13 \\
\hline IL-2 in water $+1 \mathrm{mg} / \mathrm{mL}$ EDTA & 95 & 65 & 64 & 60 & 60 & 25 & 58 & 42 \\
\hline IL-2 in water $+5 \mathrm{mg} / \mathrm{mL}$ Met & 93 & 81 & 71 & 71 & 77 & 0 & 62 & 46 \\
\hline IL-2 in water $+5 \mathrm{mg} / \mathrm{mL}$ His & 79 & 81 & 63 & 55 & 33 & 0 & 67 & 13 \\
\hline IL-2 in water $+5 \mathrm{mg} / \mathrm{mL}$ Gly & 82 & 74 & 64 & 53 & 49 & 0 & 52 & 0 \\
\hline
\end{tabular}

Figures 3-6 show the findings of the IL-2 percent recovery calculation.

\subsection{Effect of Antioxidants on IL-2 Stability in Aqueous Solutions}

To minimize or reduce the increase in oxidized product or any other possible oxidized forms of IL-2, we evaluated two antioxidants, EDTA and Met. Because the antioxidant activity of these excipients varies depending on the protein to be stabilized, they were chosen on a basis in evidence [10] [22]. The results indicated that EDTA appreciably elevated the stability of IL-2 in CTS, RPMI, PBS, and water for up to 5 days at $37^{\circ} \mathrm{C}$. The findings of short- and long-term stability tests in aqueous solutions in the presence of EDTA at various temperatures are summarized in Table 2, Table 3 and Figures 3-6. The chelating chemical EDTA has been used as an antioxidant in IL-2 solutions, implying that eliminating metal ions from aqueous solutions suppresses oxidation reactions [13]. The involvement of EDTA in our experiments may have been the collection of trace amounts of metal ions in aqueous solutions, which would otherwise speed up oxidation reactions [13]. The results of this chelating agent's study showed that oxidation reactions may be effectively prevented in IL-2 aqueous solutions.

According to RP-HPLC experiments, Met boosted the stability of IL-2 in CTS, RPMI, and water for up to 5 days at $37^{\circ} \mathrm{C}$. The findings of short- and long-term stability testing in aqueous solutions in the presence of Met at various temperatures 


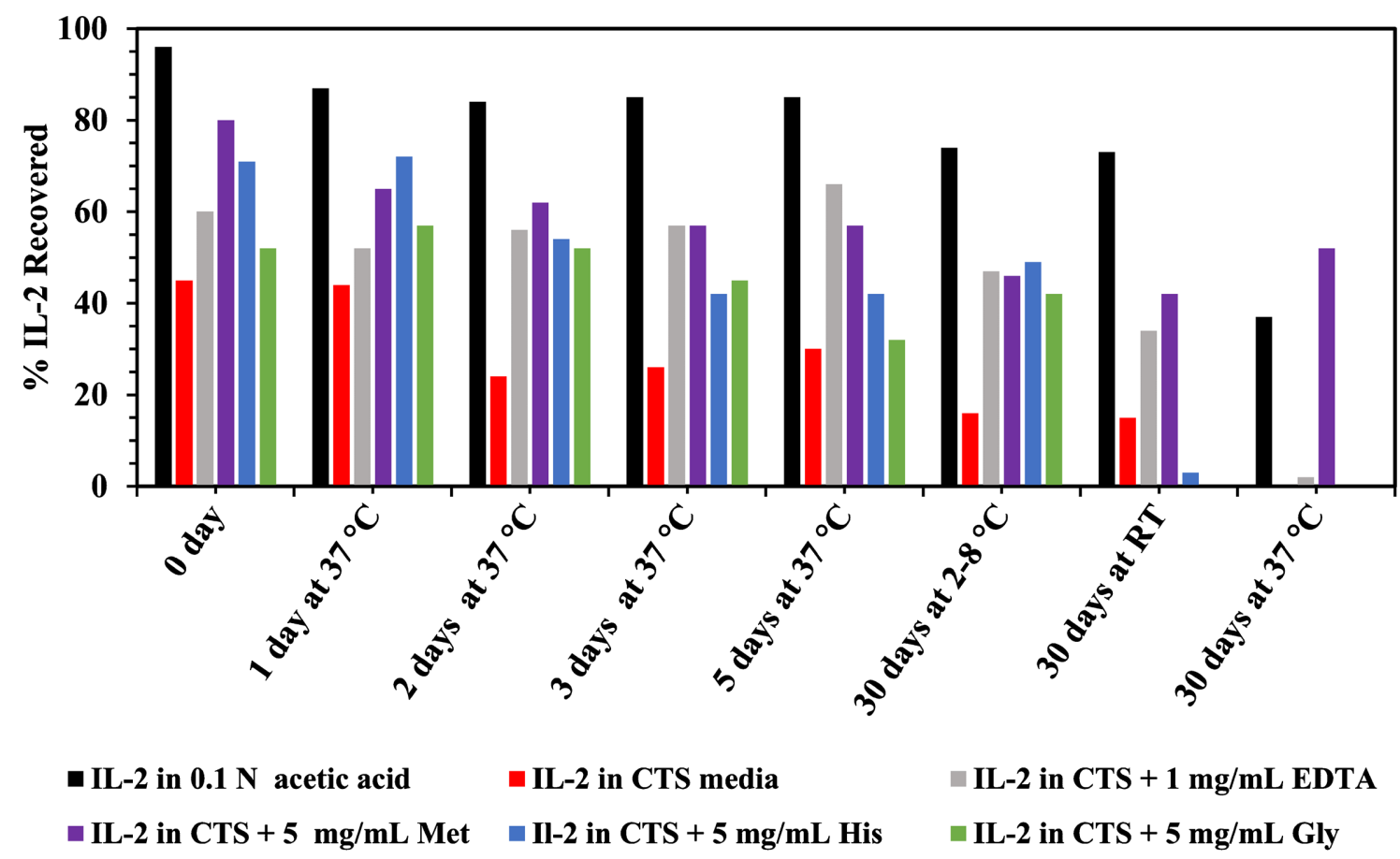

Figure 3. Effect of excipients on IL-2 stability in CTS. IL-2 was prepared in CTS in the presence of EDTA, Met, His and Gly in separate glass vials. These stability sample vials were incubated for $0,1,2,3$ and 5 days at $37^{\circ} \mathrm{C}$, for long term stability of IL-2 solutions were incubated at different temperatures $\left[2^{\circ} \mathrm{C}-8^{\circ} \mathrm{C}, \mathrm{RT}\left(20^{\circ} \mathrm{C} \pm 2^{\circ} \mathrm{C}\right)\right.$ and $\left.37^{\circ} \mathrm{C}\right]$ over a period of up to 30 days. Periodically all the stability samples were analyzed by RP-HPLC and percent recovery of IL- 2 was calculated.

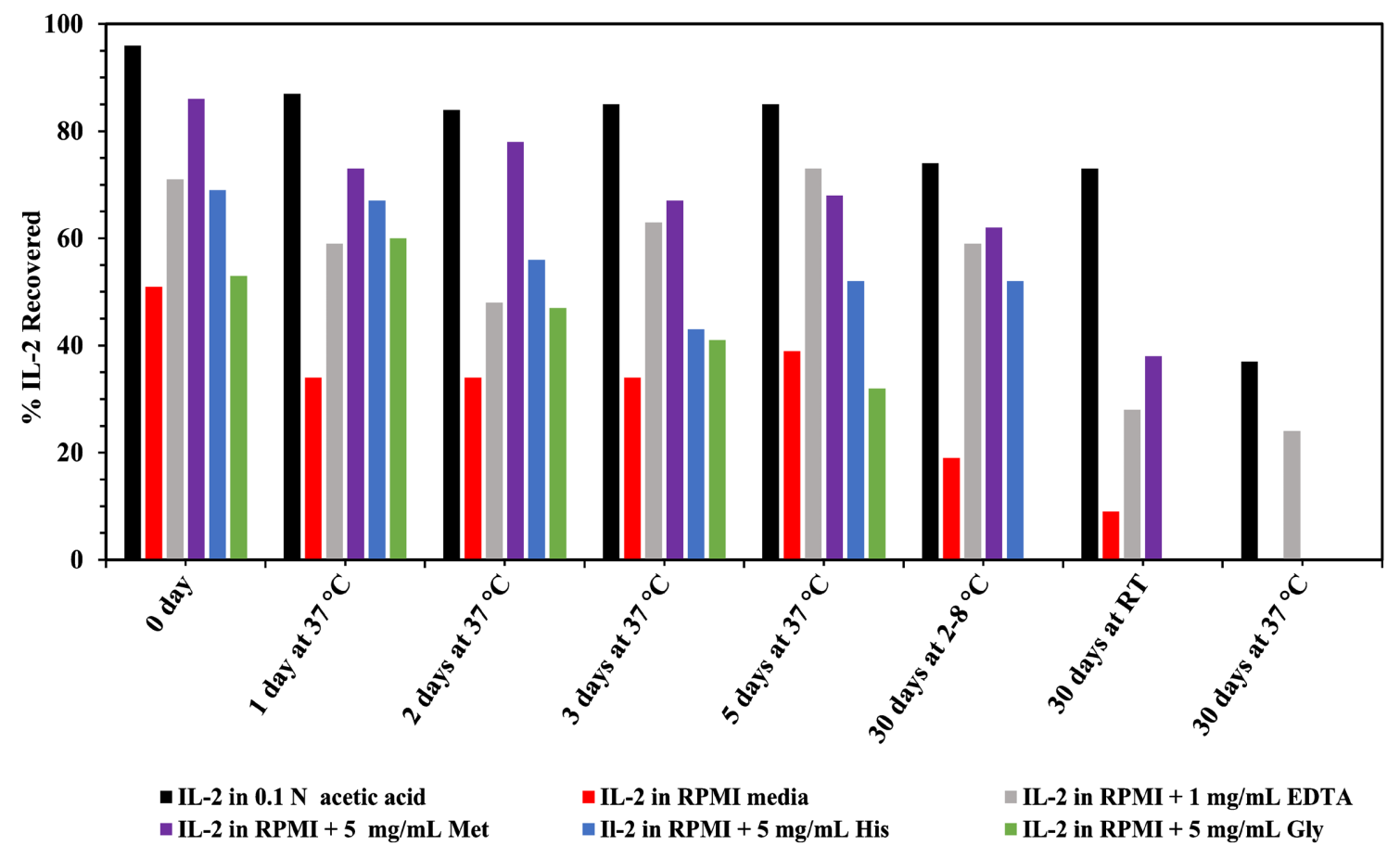

Figure 4. Effect of excipients on IL-2 stability in RPMI. IL-2 was prepared in RPMI in the presence of a EDTA, Met, His and Gly in separate glass vials. These stability sample vials were incubated for $0,1,2,3$ and 5 days at $37^{\circ} \mathrm{C}$, for long term stability of IL-2 solutions were incubated at different temperatures $\left[2^{\circ} \mathrm{C}-8^{\circ} \mathrm{C}, \mathrm{RT}\left(20^{\circ} \mathrm{C} \pm\right.\right.$ $2^{\circ} \mathrm{C}$ ) and $37^{\circ} \mathrm{C}$ ] over a period of up to 30 days. Periodically all the stability samples were analyzed by RP-HPLC and percent recovery of IL-2 was calculated. 


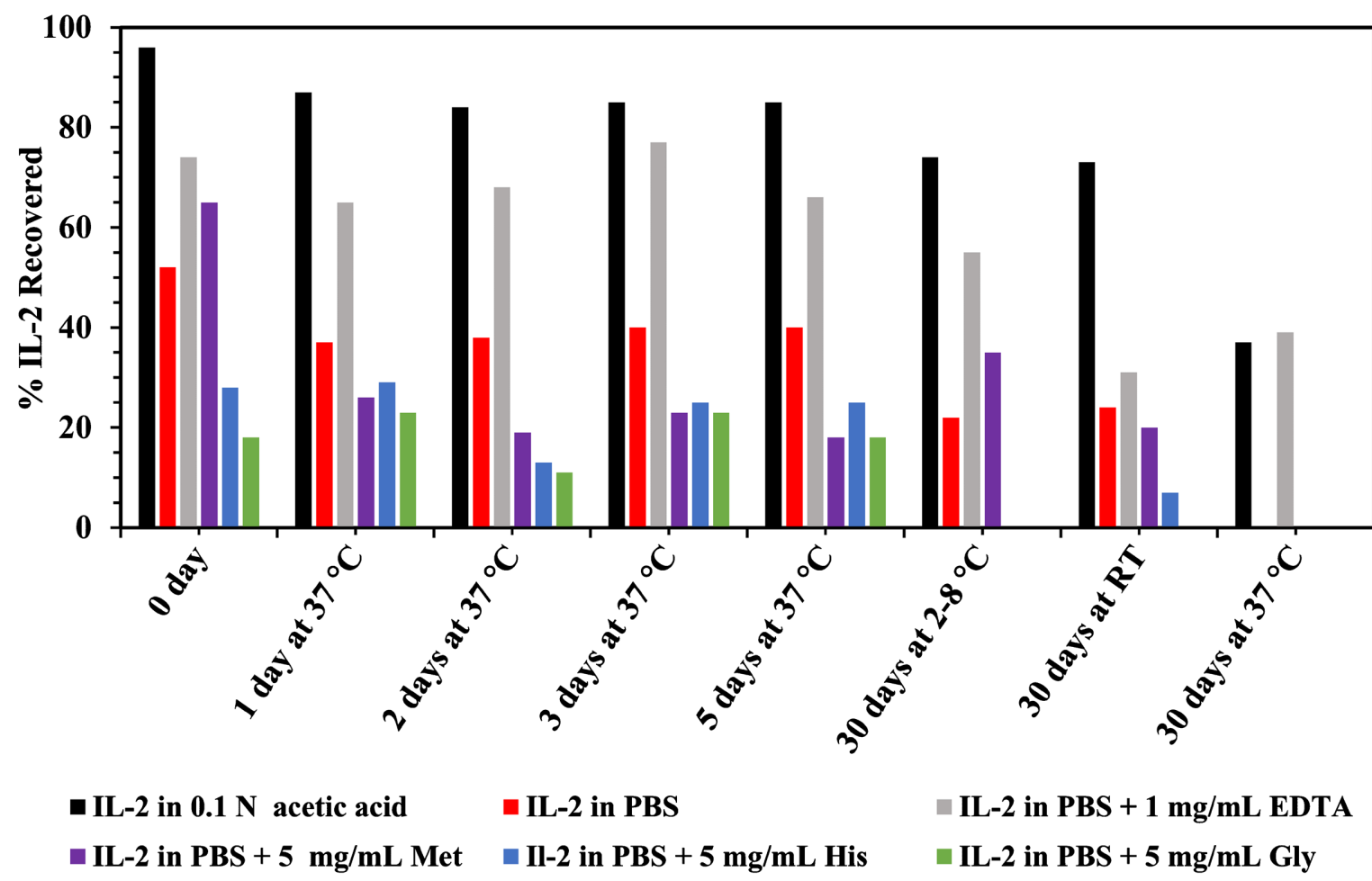

Figure 5. Effect of excipients on IL-2 stability in PBS. IL-2 was prepared in PBS in the presence of EDTA, Met, His and Gly in separate glass vials. These stability sample vials were incubated for $0,1,2,3$ and 5 days at $37^{\circ} \mathrm{C}$, for long term stability of IL-2 solutions were incubated at different temperatures $\left[2^{\circ} \mathrm{C}-8^{\circ} \mathrm{C}\right.$, RT $\left(20^{\circ} \mathrm{C} \pm 2^{\circ} \mathrm{C}\right)$ and $\left.37^{\circ} \mathrm{C}\right]$ over a period of up to 30 days. Periodically all the stability samples were analyzed by RP-HPLC and percent recovery of IL- 2 was calculated.

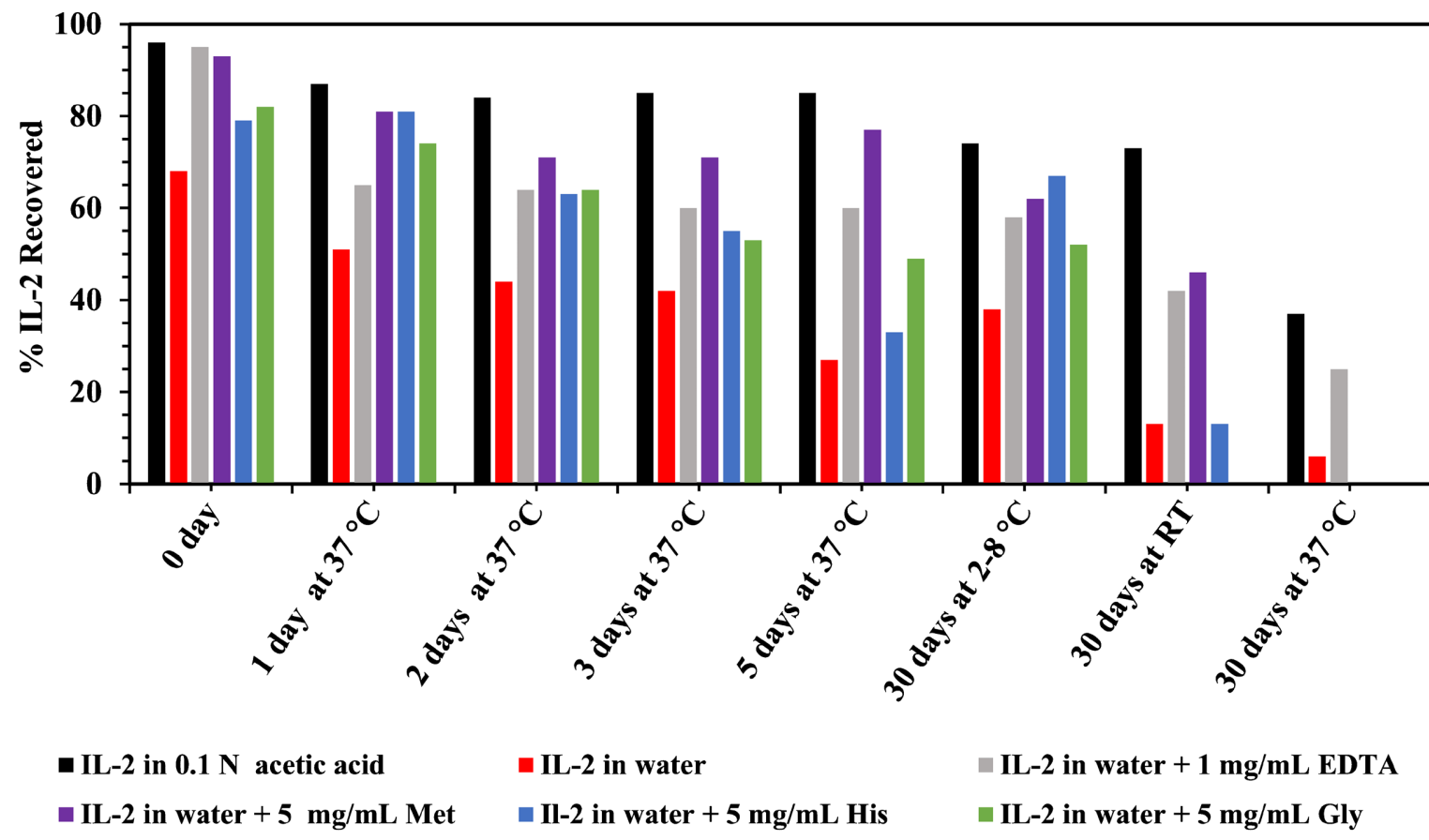

Figure 6. Effect of excipients on IL-2 stability in water. IL-2 was prepared in water in the presence of EDTA, Met, His and Gly in separate glass vials. These stability sample vials were incubated for $0,1,2,3$ and 5 days at $37^{\circ} \mathrm{C}$, for long term stability of IL-2 solutions were incubated at different temperatures $\left[2^{\circ} \mathrm{C}-8^{\circ} \mathrm{C}\right.$, RT $\left(20^{\circ} \mathrm{C} \pm 2{ }^{\circ} \mathrm{C}\right)$ and $\left.37^{\circ} \mathrm{C}\right]$ over a period of up to 30 days. Periodically all the stability samples were analyzed by RP-HPLC and percent recovery of IL- 2 was calculated. 
are presented in Table 2, Table 3 and Figures 3-5. Met may function as intrinsic reactive oxygen species scavengers in aqueous solutions, protecting IL-2 from oxidative destruction, according to these findings. Met, on the other hand, can prevent IL-2 oxidation in in vitro cell treatment medium like CTS and RPMI by acting as a competitive antioxidant. Under any of the temperature conditions, Met had no effect on IL-2 stability in PBS (Table 3 and Figure 5). Met oxidation may be accelerated by the presence of high ionic strength, oxygen, and oxygen radicals in PBS. Met is a sulfur-containing amino acid that is found in proteins. The primary chemical breakdown product of IL-2 has been identified as met-104 sulfoxide IL-2 [14] [23]. Met is a significant oxidant scavenger because it can react with a wide range of oxidants to produce methionine sulfoxide [24]. In these studies, antioxidants like EDTA and Met were found to reduce IL-2 oxidation. Although both EDTA and Met were effective at maintaining IL-2 stability in CTS and RPMI solutions prepared as described in the experimental section, this suggests that the IL-2 solution preparation technique was appropriate for the cells' treatment.

In addition, several concentrations of $\operatorname{EDTA}(0.5,1.0,2.0$, and $4 \mathrm{mg} / \mathrm{mL})$ and Met (5.0 and $7.5 \mathrm{mg} / \mathrm{mL}$ ) in aqueous solutions (CTS, RPMI, and PBS) were chosen and examined to see if their stabilizing impact on IL-2 in aqueous solutions was concentration dependent. Higher concentrations of these antioxidants did not significantly boost IL-2 stability in any of the aqueous solutions at $37^{\circ} \mathrm{C}$, according to our findings (data not shown).

Furthermore, in order to examine the stability of IL-2, a combination of more than two excipients has been tried in the hopes of addressing different stability concerns via different pathways and/or a possible synergistic effect. A combination of EDTA $(1 \mathrm{mg} / \mathrm{mL})$, Met $(5 \mathrm{mg} / \mathrm{mL})$, and Gly $(5 \mathrm{mg} / \mathrm{mL})$ in aqueous solutions (CTS, RPMI, and PBS) may stabilize IL-2 in aqueous solutions (CTS, RPMI, and PBS) to the same degree as using each excipient individually at $37^{\circ} \mathrm{C}$. We discovered that the stability of IL-2 did not improve (data not shown).

\subsection{Effect of Amino Acids on IL-2 Stability in Aqueous Solutions}

The protein stability of therapeutic IL-2 is influenced by its storage and distribution. Amino acid additions can be made at any point during the manufacturing and storage processes to help stabilize proteins. Proteins have been shown to be stabilized through an exclusion process in which specific amino acids hydrate the protein in solution preferentially [13]. The purpose was to see how the bulking components His and Gly, which are routinely employed in pharmaceutical protein formulations, affected IL-2 stability in aqueous solutions. In CTS, RPMI, PBS, and water, His and Gly were found to act as IL-2 buffering agents. The effect of His and Gly in stabilizing IL-2 in aqueous solutions was investigated using RP-HPLC and SDS-PAGE, as previously mentioned. At any temperature, Gly had no effect on CTS or RPMI, but His improved the stability of IL-2 in CTS and RPMI for up to 5 days at $37^{\circ} \mathrm{C}$. However, in PBS and water, both amino ac- 
ids enhanced IL-2 stability either slightly or not at all (Table 3 and Figure 5, Figure 6). The findings of short- and long-term stability tests in aqueous solutions in the presence of His and Gly at various temperatures are shown in Table 2, Table 3 and Figures 3-6. Amino acids have been studied extensively to see if they can aid in protein stabilization. A number of amino acids, including aromatic, basic, and acidic amino acids, as well as Met, have been shown to help in the stabilization of recombinant human interferon alpha-2b [25], while glutamic and aspartic acids have been shown to extend the half-life of recombinant human keratinocyte growth factor [26]. Although the features of the protein that has to be stabilized are likely to have an impact on the stabilizing effect of amino acids. In contrast to Gly in CTS and RPMI during cell treatment conditions, our data showed that His was the most effective excipient in retaining the stability of IL-2.

More investigation was performed to see whether the N-acetylcysteine (NAC), N, N'-diacetyl-L-cysteine (Di-NAC), Triton X-100 [27] [28], and -mercaptoethanol [27] [28] affected IL-2 stability in aqueous solutions. In aqueous environments, these excipients exhibit low IL-2 stability (data not shown). Under alkaline conditions, NAC, Di-NAC, and -mercaptoethanol may cause disulfide bond disruption and interchain disulfide link reconfiguration in IL-2, making the protein unstable and prone to conformational changes. These reducing agents, on the other hand, tend to be poor excipients for IL-2 aqueous solution stability. Non-ionic surfactants, on the other hand, are frequently utilized in protein pharmaceutical formulations to limit protein surface absorption and avoid agglomeration. Triton X-100 contains a hydrophobic p-octylphenyl group and a polyethylene glycol chain that degrades spontaneously via autooxidation and hydrolysis [27] [28]. Triton X-100 cannot be utilized to keep IL-2 stable in aqueous solutions because peroxides have a significant impact on protein oxidation and aggregation [29]. Excipients such as EDTA, Met, His, and Gly may affect IL-2 bioactivity, implying that increased stability does not always imply increased bioactivity. Because the bioactivity of IL-2 in the presence of excipients was not investigated, the potential of IL-2 to boost the survival and proliferation of an IL-2 dependent cell line was not examined in this study.

\subsection{SDS-PAGE Analysis}

In order to understand the RP-HPLC findings, we performed an additional stability-indicating SDS-PAGE experiment to examine the impact of each antioxidant (EDTA and Met) and amino acid (His and Gly) on IL-2 stability in aqueous medium. SDS-PAGE was used to examine the short-term stability samples on days $0,1,2,3$, and 5 at $37^{\circ} \mathrm{C}$, as well as the long-term stability sample solutions in CTS, RPMI, PBS, and water with excipients for 30 days at varied temperatures $\left[2^{\circ} \mathrm{C}-8^{\circ} \mathrm{C}\right.$, RT $\left(20^{\circ} \mathrm{C} \pm 2^{\circ} \mathrm{C}\right)$ and $\left.37^{\circ} \mathrm{C}\right]$. IL-2 migrated in a single band with a molecular weight of around $15 \mathrm{kDa}$ in all stability tests under reducing conditions. Short- and long-term stability studies in aqueous solutions containing antioxidants and amino acids at various temperatures are shown in Figures 7-11 and 
Figures S1-S3. Surprisingly, IL-2's stability did not deteriorate over time in a variety of aqueous solutions and temperatures. As a result, the intensity of the IL-2 bands did not vary significantly. Under reduced conditions, not all of the IL-2

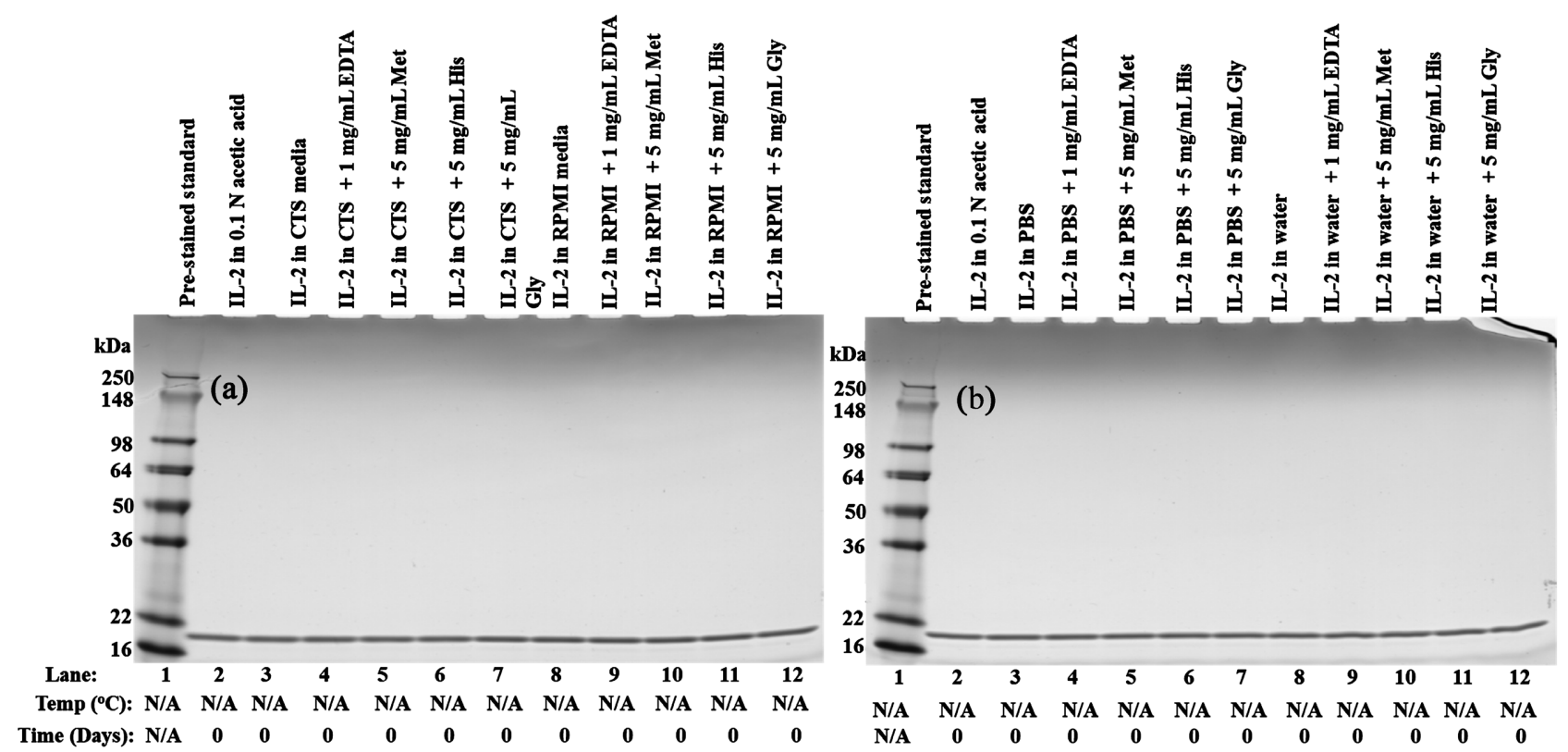

Figure 7. Effect of excipients on IL-2 stability in freshly prepared aqueous solutions. In separate vials, IL-2 was prepared in (a) CTS and RPMI, (b) PBS and water in the presence of EDTA, Met, His and Gly. The conformational stability was characterized by SDS-PAGE.

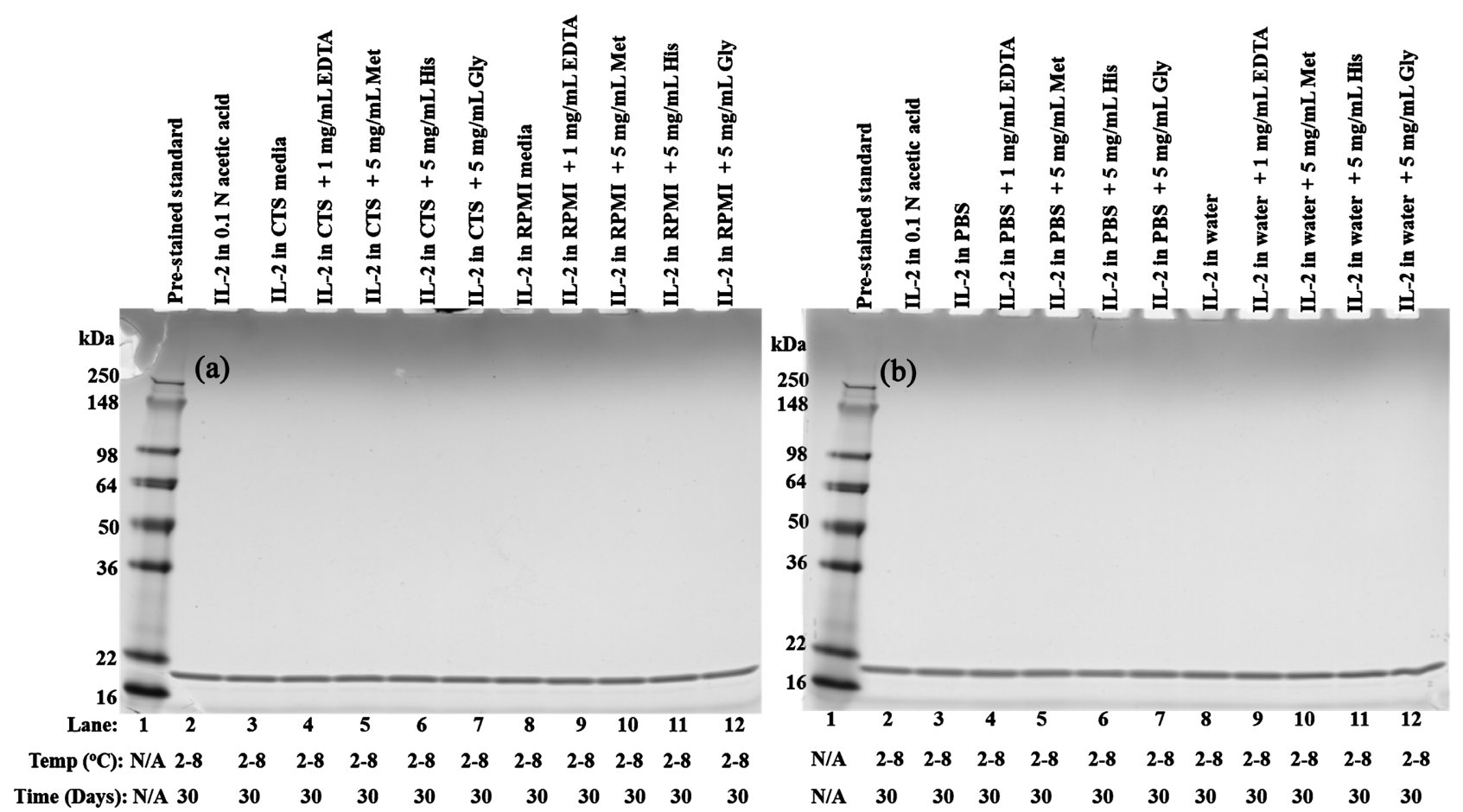

Figure 8. Effect of excipients on IL-2 stability in aqueous solutions after 30 days incubation at $2^{\circ} \mathrm{C}-8^{\circ} \mathrm{C}$. In separate vials, IL-2 was prepared in (a) CTS and RPMI, (b) PBS and water in the presence of EDTA Met, His and Gly. All vials were incubated for 30 days at $2^{\circ} \mathrm{C}-8^{\circ} \mathrm{C}$. The conformational stability was characterized by SDS-PAGE. 


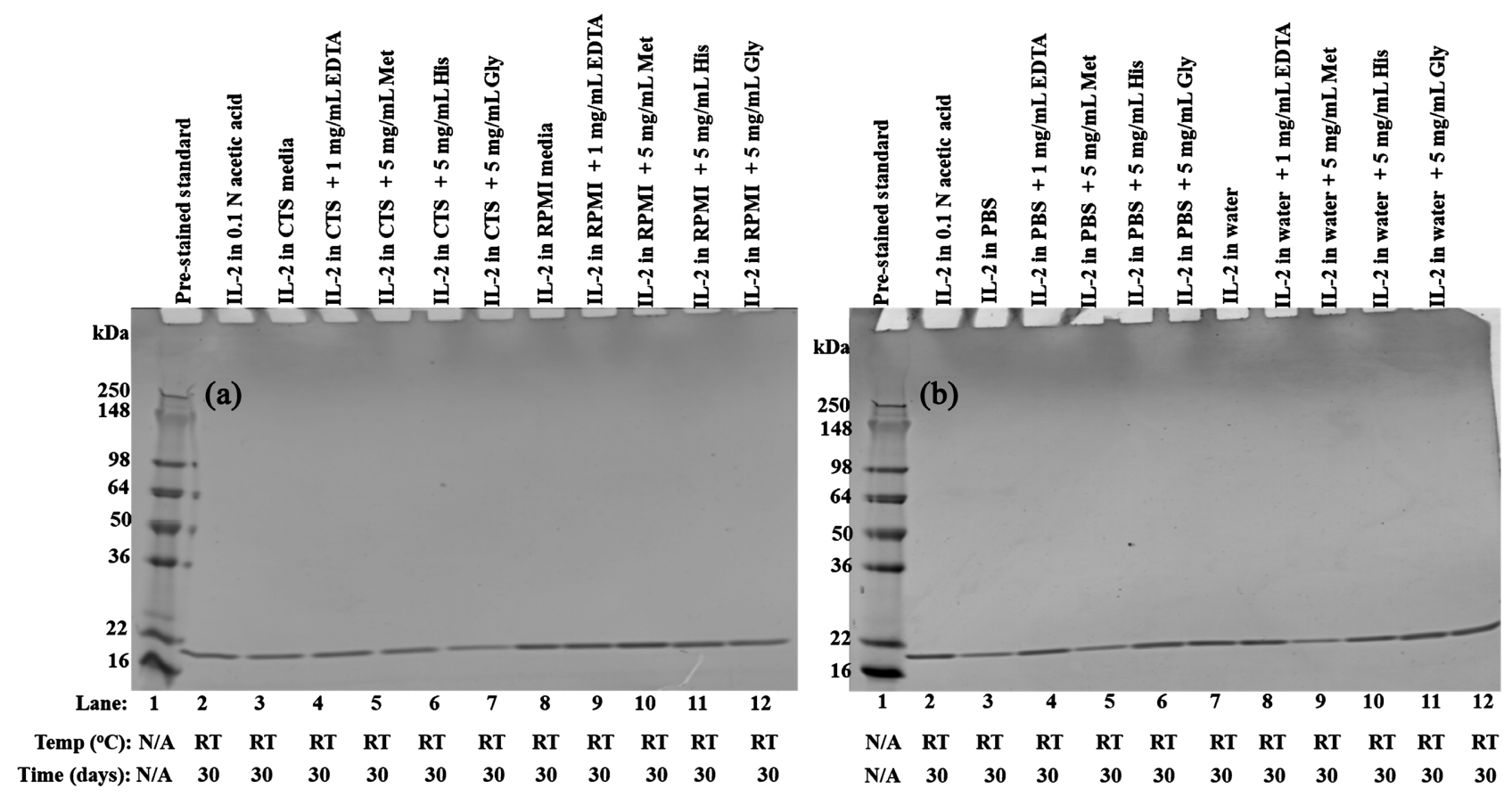

Figure 9. Effect of excipients on IL-2 stability in aqueous solutions after 30 days incubation at $\mathrm{RT}\left(20^{\circ} \mathrm{C} \pm 2{ }^{\circ} \mathrm{C}\right)$. In separate vials, IL-2 was prepared in (a) CTS and RPMI, (b) PBS and water in the presence of EDTA Met, His and Gly. All vials were incubated for 30 days at $\mathrm{RT}\left(20^{\circ} \mathrm{C} \pm 2^{\circ} \mathrm{C}\right)$. The conformational stability was characterized by SDS-PAGE.

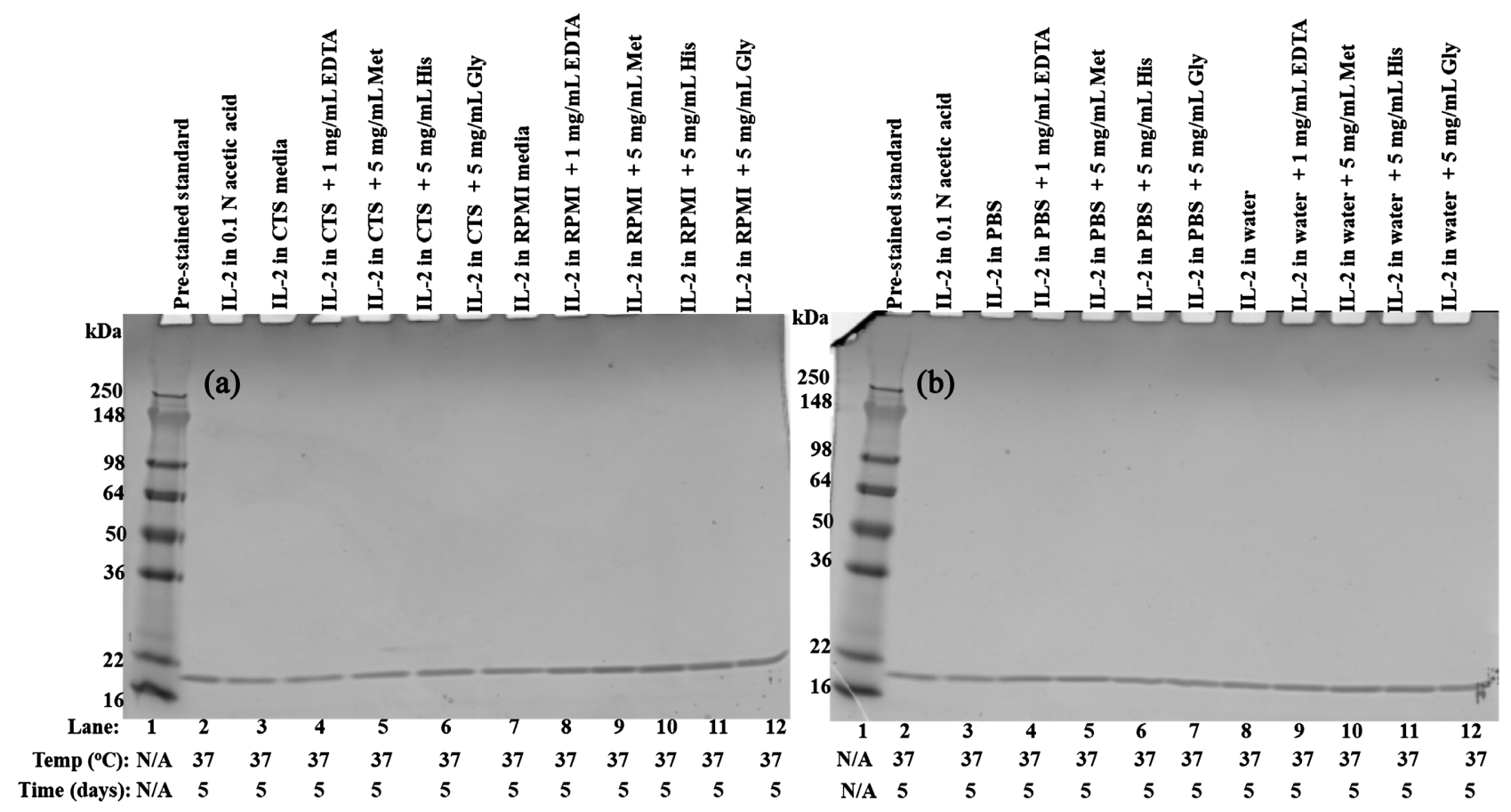

Figure 10. Effect of excipients on IL-2 stability in aqueous solutions after 5 days incubation at $37^{\circ} \mathrm{C}$. In separate vials, IL-2 was prepared in (a) CTS and RPMI, (b) PBS and water in the presence of EDTA Met, His and Gly. All vials were incubated for 5 days at $37^{\circ} \mathrm{C}$. The conformational stability was characterized by SDS-PAGE.

stability samples showed visible precipitates and residual dimers, indicating that non-disulfide cross-linking of IL-2 was not present or that the sample preparation 


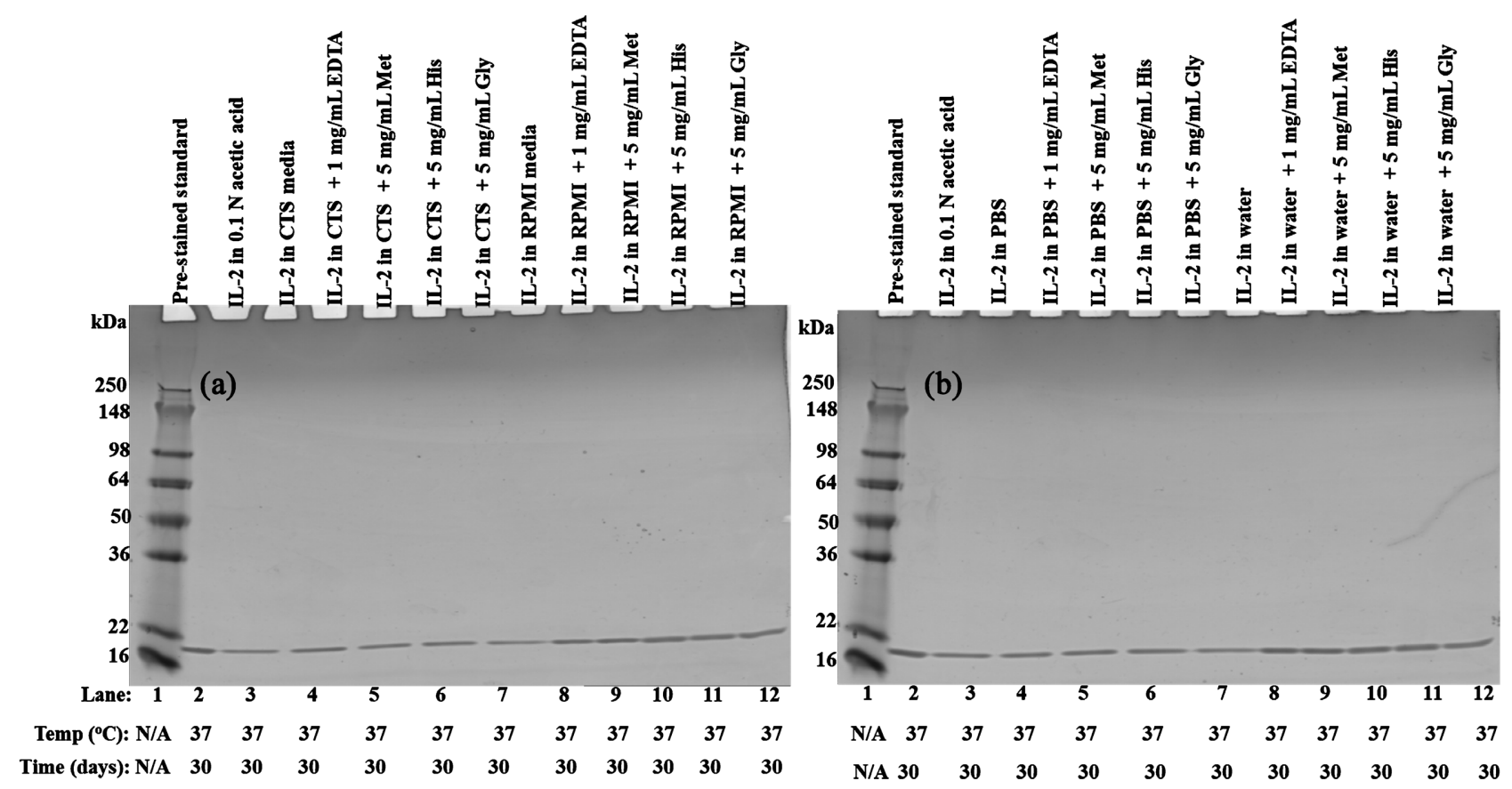

Figure 11. Effect of excipients on IL-2 stability in aqueous solutions after 30 days incubation at $37^{\circ} \mathrm{C}$. In separate vials, IL-2 was prepared in (a) CTS and RPMI, (b) PBS and water in the presence of EDTA Met, His and Gly. All vials were incubated for 30 days at $37^{\circ} \mathrm{C}$. The conformational stability was characterized by SDS-PAGE.

process used too much reducing agent, resulting in complete reduction. When the amount of reducing agent in the sample buffer was decreased (data not shown), no precipitates or dimer bands were seen, suggesting that non-disulfide cross-linking interactions did not occur. Because no protein aggregation bands exist in this condition, it's likely that precipitates formed physically and then disintegrated entirely in SDS sample buffer under sample conditions. Soluble or insoluble aggregates, reversible or irreversible aggregates, covalent or noncovalent aggregates are all possibilities [30].

\section{Discussion}

While IL-2 is an effective anticancer therapeutic in humans and a growth factor for T cells, its unstability makes it more difficult to use in liquid form. Quantitative measurement of IL-2 is widely used in the pharmaceutical industry and research institutes because its ability to directly affect human health can be demonstrated. To solve this challenge, researchers must investigate the effect of excipients on IL-2 stability in a variety of aqueous solutions with adequate stability. The capacity of EDTA, Met, His, and Gly to maintain IL-2 stable in aqueous solutions was investigated in this work. The major goal of this work was to see how excipient-induced stability impacts IL-2 levels in CTS and RPMI, which are both often utilized to grow $\mathrm{T}$ cells in research facilities. We selected RP-HPLC measurement of soluble IL-2 as the stability indicating test since the bioassay for IL-2 was insensitive.

Because the IL-2 samples were prepared from aqueous solutions, it was crit- 
ical that the samples' matrices did not interfere with the IL-2 detection during the 20-minute run period. Under specified chromatographic conditions, IL-2 was eluted in four separate aqueous solutions at different temperatures in one peak at 7.2 minutes (Figures S4-S7). Throughout the stability investigation, RP-HPLC did not find any degradation products or visible IL-2 precipitates, however the concentration of soluble IL-2 in the stability samples dropped over time. The content of soluble IL-2 decreased, most likely due to the formation of precipitates. Ionic complexation, salting out, charge neutrality around the isoelectric $\mathrm{pH}$, and IL-2 solubility limitation are some of the additional non-covalent aggregation mechanisms. The stability of IL-2 incubated in acetic acid was unaffected by temperature, indicating that an acidic $\mathrm{pH}$ can reduce oxidative reactivity.

Stability tests reveal the possibility of IL-2 loss following the treatment of cells with supplement medium. However, we looked at how two antioxidants, EDTA and Met, affected IL-2 stability in four different aqueous solutions at different temperatures. The IL-2 stability in all four aqueous solutions increased up to 5 days at $37^{\circ} \mathrm{C}$ in the presence of EDTA, but beyond 5 days, it dropped (data not shown). After 30 days of incubation at different temperatures $\left[2^{\circ} \mathrm{C}-8^{\circ} \mathrm{C}\right.$, RT $\left(20^{\circ} \mathrm{C} \pm 2^{\circ} \mathrm{C}\right)$ and $\left.37^{\circ} \mathrm{C}\right]$, the stability of IL-2 is shown to be decreasing. Furthermore, the highest dose of EDTA tested $(4 \mathrm{mg} / \mathrm{mL})$ had no effect on IL-2 stability in aqueous solutions. EDTA has been employed as a food and medical additive in a variety of applications, including protease inhibition [31], but it is most commonly used as a stabilizer to prevent metal-induced adverse effects. Metal ions can have a major impact on thiol group stability. When EDTA was added to a solution that included no other metals, it greatly reduced oxidative damage and enhanced thiol group stability [32].

In CTS, RPMI, and water, IL-2 became more stable in the presence of Met. In aqueous solutions, Met, on the other hand, can act as a competitive antioxidant, preventing IL-2 oxidation. In PBS with Met, the stability of Il-2 was not improved, suggesting that Phosphate buffer speeds up Met degradation more than other buffers [33], resulting in methionine sulfoxide and methionine sulfone production. Protein folding and structural stability are affected because both species are larger and more polar than nonoxidized Met [34]. After 30 days of incubation at various temperatures, the stability of IL-2 was shown to be reduced (data was not shown). The highest concentration of Met tested $(7.5 \mathrm{mg} / \mathrm{mL})$ had no effect on the IL-2 stability in aqueous solutions. Overall, these findings show that EDTA and Met can stabilize IL-2 in CTS and RPMI for up to 5 days under cell treatment conditions.

In aqueous solutions, His and Gly were found as pharmacological buffering agents for IL-2, and each amino acid was examined separately in CTS, RPMI, PBS, and water solutions. In CTS and RPMI, the amino acid His stabilized IL-2 better than the other amino acid Gly. The finding that IL-2 was unstable in aqueous solutions containing Gly was surprising. It's possible that the presence of Gly in aqueous solutions, the formation of disodium salt crystals, and $\mathrm{pH}$ 
fluctuations are interfering with IL-2 stability. Glycine in its amorphous state might also additionally stabilize a protein by preferential exclusion [35]. His has been shown in studies to be useful not just as a buffering agent, but also as a protein stabilizer in aqueous environments [36]. The most critical element [37] affecting IL-2 stability in aqueous solutions appears to be the positive charge on the sidechain of His. It's likely that the mechanism for IL-2 stabilization is the same for all basic amino acids, and that it binds transiently to IL-2 side chains, causing water populations in the solvation shell to change [37], making unfolding and aggregation less energetically beneficial. This example demonstrated that His can be used as a specific stabilizer and buffering agent for IL-2 in its aqueous form.

SDS-PAGE under reduced conditions was used to determine the conformational stability of IL-2 samples in aqueous solutions on different days at different temperatures. In any of the stability samples, the intensity of IL-2 bands did not change appreciably. In all cases, the absence of residual dimers indicates no non-disulfide cross-linking of IL-2 by aqueous solutions or complete reduction during sample preparation. Disulfide linking processes in aqueous solutions are most likely because lowering the reducing agent in the sample buffer failed to reveal the dimer band. This research investigates the stability of IL-2 in aqueous solutions under cell treatment conditions.

\section{Conclusion}

In order to analyze protein medicines in liquid form, many methods are available. Excipients including EDTA, Met, and His were shown to be very effective at stabilizing IL-2 in different buffers, $\mathrm{pH}$, and ionic strength in this study, which used an analytical approach called RP-HPLC analysis. Our findings suggest that adding EDTA, Met, and His in medical formulations and cell treatment medium can help stabilize and reduce IL-2 aggregation, and that they could be a solution to any aggregation-related manufacturing or formulation difficulties.

\section{Authors Contributions}

A.S.P.G. conceived, designed, performed the experiments and wrote manuscript. A.S. and T.S. reviewed the manuscript.

\section{Acknowledgements}

The authors wish to thank the management of Department of raw materials, Eurofins BioPharma Product Testing, Lancaster, for supporting this work.

\section{Funding Support}

This research received no external funding. This project was supported by Department of raw materials, Eurofins BioPharma Product Testing, Lancaster, PA 17601 USA. 


\section{Conflicts of Interest}

The authors declare no conflicts of interest regarding the publication of this paper.

\section{References}

[1] Morgan, D.A., Ruscetti, F.W. and Gallo, R. (1976) Selective in Vitro Growth of T Lymphocytes from Normal Human Bone Marrows. Science, 193, 1007-1008. https://doi.org/10.1126/science.181845

[2] Rosenberg, S.A., Yang, J.C., White, D.E. and Steinberg, S.M. (1998) Durability of Complete Responses in Patients with Metastatic Cancer Treated with High-Dose Interleukin-2: Identification of the Antigens Mediating Response. Annals of Surgery, 228, 307-319.

[3] Taniguchi, T., Matsui, H., Fujita, T., Takaoka, C., Kashima, N., Yoshimoto, R. and Hamuro, J. (1983) Structure and Expression of a Cloned cDNA for Human Interleukin-2. Nature, 302, 305-310. https://doi.org/10.1038/302305a0

[4] Smith, K.A. (1984) Interleukin 2. Annual Review of Immunology, 2, 319-333. https://doi.org/10.1146/annurev.iy.02.040184.001535

[5] Mark, D.F., Lin, L.S. and Lu, S.Y. (1985) Human Recombinant Interleukin-2 Muteins. United States Patent 4,518,584, May 21.

[6] Hora, M.S., Rana, R.K., Wilcox, C.L., Katre, N.V., Hirtzer, P., Wolfe, S.N. and Thomson, J.W. (1992) Development of a Lyophilized Formulation of Interleukin-2. Developments in Biological Standardization, 74, 295-303.

[7] Vemuri, S. (1992) Lyophilization Cycle Development for Interleukin-2. Developments in Biological Standardization, 74, 341-351.

[8] Carpenter, J.F., Pikal, M.J., Chang, B.S. and Randolph, T.W. (1997) Rational Design of Stable Lyophilized Protein Formulations: Some Practical Advice. Pharmaceutical Research, 14, 969-975. https://doi.org/10.1023/A:1012180707283

[9] Cadée, J.A., van Steenbergen, M.J., Versluis, C., Heck, A.J., Underberg, W.J., den Otter, W., Jiskoot, W. and Hennink, W.E. (2001) Oxidation of Recombinant Human Interleukin-2 by Potassium Peroxodisulfate. Pharmaceutical Research, 18, 1461-1467. https://doi.org/10.1023/A:1012213108319

[10] Reyes, N., Ruiz, L., Aroche, K., Gerónimo, H., Brito, O. and Hardy, E. (2005) Stability of Ala 125 Recombinant Human Interleukin-2 in Solution. Journal of Pharmacy and Pharmacology, 57, 31-37. https://doi.org/10.1211/0022357055182

[11] Gounili, P.K. (1999) The Effect of $\mathrm{pH}$ and Temperature on the Conformational Stability of Recombinant Human Interleukin-2. Doctoral Dissertations, AAI9942575. https://opencommons.uconn.edu/dissertations/AAI9942575

[12] Vlasveld, L.T., Beijnen, J.H., Sein, J.J., Rankin, E.M., Melief, C.J. and Hekman, A. (1993) Reconstitution of Recombinant Interleukin-2 (rIL-2): A Comparative Study of Various rIL-2 Muteins. European Journal of Cancer, 29, 1977-1979. https://doi.org/10.1016/0959-8049(93)90456-P

[13] Wang, W. (1999) Instability, Stabilization, and Formulation of Liquid Protein Pharmaceuticals. International Journal of Pharmaceutics, 185, 129-188. https://doi.org/10.1016/S0378-5173(99)00152-0

[14] Kunitani, M., Hirtzer, P., Johnson, D., Halenbeck, R., Boosman, A. and Koths, K. (1986) Reversed-Phase Chromatography of Interleukin-2 Muteins. Journal of Chromatography A, 359, 391-402. https://doi.org/10.1016/0021-9673(86)80093-0

[15] Duncan, M. (1995) Influence of Surfactants upon Protein/Peptide Adsorption to 
Glass and Polypropylene. International Journal of Pharmaceutics, 120, 179-188. https://doi.org/10.1016/0378-5173(94)00402-Q

[16] Medvec Medvec, A.R., Ecker, C., Kong, H., Winters, E.A., Glover, J., Varela-Rohena, A. and Riley, J.L. (2017) Improved Expansion and in Vivo Function of Patient T Cells by a Serum-free Medium. Molecular Therapy-Methods \& Clinical Development, 8, 65-74. https://doi.org/10.1016/j.omtm.2017.11.001

[17] Wei, T., Kaewtathip, S. and Shing, K. (2009) Effect on Protein Adsorption at Liquid/Solid Interface. The Journal of Physical Chemistry, 113, 2053-2062. https://doi.org/10.1021/jp806586n

[18] Prakasha Gowda, A.S., Schaefer, A.D. and Schuck, T.K. (2020) A Simple RP-HPLC Method for the Stability-Indicating Determination of $\mathrm{N}$-acetyl-L-cysteine and N,N'-diacetyl-L-cystine in Cell Culture Media. Cell \& Gene Therapy Insights, 6, 303-323. https://doi.org/10.18609/cgti.2020.041

[19] Laemmli, U.K. (1970) Cleavage of Structural Proteins during the Assembly of the Head of Bacteriophage T4. Nature, 227, 680-685. https://doi.org/10.1038/227680a0

[20] Johnston, T.P. (1996) Adsorption of Recombinant Human Granulocyte Colony Stimulating Factor (rhG-CSF) to Polyvinyl Chloride, Polypropylene, and Glass: Effect of Solvent Additives. PDA Journal of Pharmaceutical Science and Technology, 50, 238-245.

[21] Tzannis, S.T., Hrushesky, W.J.M., Wood, P.A. and Przybycien, T.M. (1997) Adsorption of a Formulated Protein on a Drug Delivery Device Surface. Journal of Colloid and Interface Science, 189, 216-228. https://doi.org/10.1006/jcis.1997.4841

[22] Andersson, M.M., Breccia, J.D. and Hatti-Kaul, R. (2000) Stabilizing Effect of Chemical Additives against Oxidation of Lactate Dehydrogenase. Biotechnology and Applied Biochemistry, 32, 145-153. https://doi.org/10.1042/BA20000014

[23] Moya, G., González, L.J., Huerta, V., García, Y., Morera, V., Pérez, D., Breña, F. and Araña, M. (2002) Isolation and Characterization of Modified Species of a Mutated (Cys125-Ala) Recombinant Human Interleukin-2. Journal of Chromatography $A$, 971, 129-142. https://doi.org/10.1016/S0021-9673(02)00845-2

[24] Levine, R.L., Mosoni, L., Berlett, B.S. and Stadtman, E.R. (1996) Methionine Residues as Endogenous Antioxidants in Proteins. Proceedings of the National Academy of Sciences of the United States of America, 93, 15036-15040. https://doi.org/10.1073/pnas.93.26.15036

[25] Sebeka, H.K., Starkuviene, B., Trepsiene, O.V., Pauliukonis, A.A. and Bumelis, V.A. (2001) Comparative Effects of Stabilizing Additives on the Rates of Heat Inactivation of Recombinant Human Interferon Alpha-2b in Solution. Antiviral Research, 50, 117-127. https://doi.org/10.1016/S0166-3542(01)00131-0

[26] Chen, B.L., Arakawa, T., Hsu, E., Narhi, L.O., Tressel, T.J. and Chien, S.L. (1994) Strategies to Suppress Aggregation of Recombinant Keratinocyte Growth Factor during Liquid Formulation Development. Journal of Pharmaceutical Sciences, 83, 1657-1661. https://doi.org/10.1002/jps.2600831204

[27] Choi, N.S., Hahm, J.H., Maeng, P.J. and Kim, S.H. (2005) Comparative Study of Enzyme Activity and Stability of Bovine and Human Plasmins in Electrophoretic Reagents, Beta-Mercaptoethanol, DTT, SDS, Triton X-100, and Urea. Journal of Biochemistry and Molecular Biology, 38, 177-181. https://doi.org/10.5483/BMBRep.2005.38.2.177

[28] Donbrow, M., Hamburger, R. and Azaz, E. (1975) Surface Tension and Cloud Point Changes of Polyoxyethylenic Non-Ionic Surfactants during Autoxidation. Journal of Pharmacy and Pharmacology, 27, 160-166. 
https://doi.org/10.1111/j.2042-7158.1975.tb09430.x

[29] Koley, D. and Bard, A.J. (2010) Triton X-100 Concentration Effects on Membrane Permeability of a Single HeLa Cell by Scanning Electrochemical Microscopy (SECM). Proceedings of the National Academy of Sciences of the United States of America, 107, 16783-16787. https://doi.org/10.1073/pnas.1011614107

[30] Cromwell, M.E., Hilario, E. and Jacobson, F. (2006) Protein Aggregation and Bioprocessing. The AAPS Journal, 8, E572-E579. https://doi.org/10.1208/aapsj080366

[31] Grabski, A.C. (2009) Advances in Preparation of Biological Extracts for Protein Purification. Methods in Enzymology, 463, 285-303.

https://doi.org/10.1016/S0076-6879(09)63018-4

[32] Ellman, G.L. (1959) Tissue Sulfhydryl Groups. Archives of Biochemistry and Biophysics, 82, 70-77. https://doi.org/10.1016/0003-9861(59)90090-6

[33] Chang, S.H., Teshima, G.M., Milby, T., Gillece-Castro, B. and Canova-Davis, E. (1997) Metal-Catalyzed Photooxidation of Histidine in Human Growth Hormone. Analytical Biochemistry, 244, 221-227. https://doi.org/10.1006/abio.1996.9899

[34] Jones, C. (1981) Sulfur in Proteins: by Y M Torchinsky (Translated by W Wittenberg). pp 294. Pergamon Press, Oxford. (Original in Russian, 1977). \$96 ISBN 0-08-023778-9. Biochemical Education, 10, 123.

https://www.sciencedirect.com/science/article/pii/030744128290108X https://doi.org/10.1016/0307-4412(82)90108-X

[35] Pikal-Cleland, K.A., Cleland, J.L., Anchordoquy, T.J. and Carpenter, J.F. (2002) Effect of Glycine on $\mathrm{pH}$ Changes and Protein Stability during Freeze-Thawing in Phosphate Buffer Systems. Journal of Pharmaceutical Sciences, 91, 1969-1979. https://doi.org/10.1002/jps.10184

[36] Chen, B., Bautista, R., Yu, K., Zapata, G.A., Mulkerrin, M.G. and Chamow, S.M. (2003) Influence of Histidine on the Stability and Physical Properties of a Fully Human Antibody in Aqueous and Solid Forms. Pharmaceutical Research, 20, 1952-1960. https://doi.org/10.1023/B:PHAM.0000008042.15988.c0

[37] Falconer, R.J., Chan, C., Hughes, K. and Munro, T.P. (2011) Stabilization of a Monoclonal Antibody during Purification and Formulation by Addition of Basic Amino Acid Excipients. Journal of Chemical Technology \& Biotechnology, 86, 942-948. https://doi.org/10.1002/jctb.2657

\section{Abbreviations}

Recombinant interleukin-2 (IL-2), Ethylenediaminetetraacetic acid (EDTA), L-Histidine monohydrochloride (His), Glycine hydrochloride (Gly), L-methionine (Met), Acetonitrile (ACN), Trifluoroacetic Acid (TFA), Sodium dodecyl sulfate (SDS), Phosphate buffer saline (PBS), Cell Therapy Systems (CTS), Roswell Park Memorial Institute (RPMI), room temperature (RT), Reversed-Phase-High Performance Liquid Chromatography (RP-HPLC), sodium dodecyl sulphate polyacrylamide gel electrophoresis (SDS-PAGE), N-acetylcysteine (NAC), N,N'-diacetylL-cystine (Di-NAC), sodium chloride $(\mathrm{NaCl})$. 


\section{Appendix}

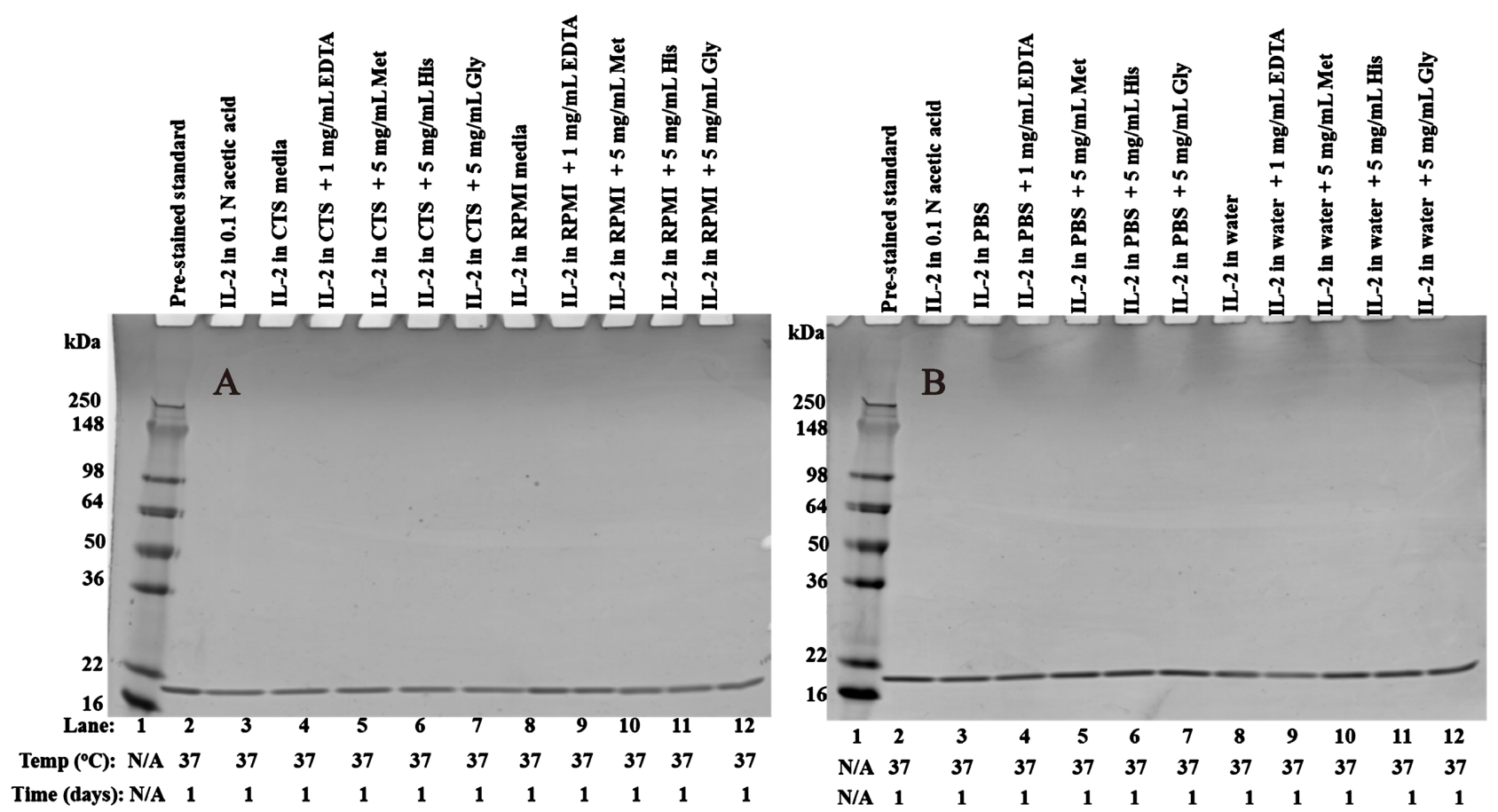

Figure S1. Effect of excipients on IL-2 stability in aqueous solutions after 1 day incubation at $37^{\circ} \mathrm{C}$. In separate vials, $1 \mu \mathrm{g}$ of IL-2 were prepared in (A) CTS and RPMI, (B) PBS and water in the presence of EDTA, Met, His and Gly. All vials were incubated for 1 day at $37^{\circ} \mathrm{C}$. The conformational stability was characterized by SDS-PAGE.

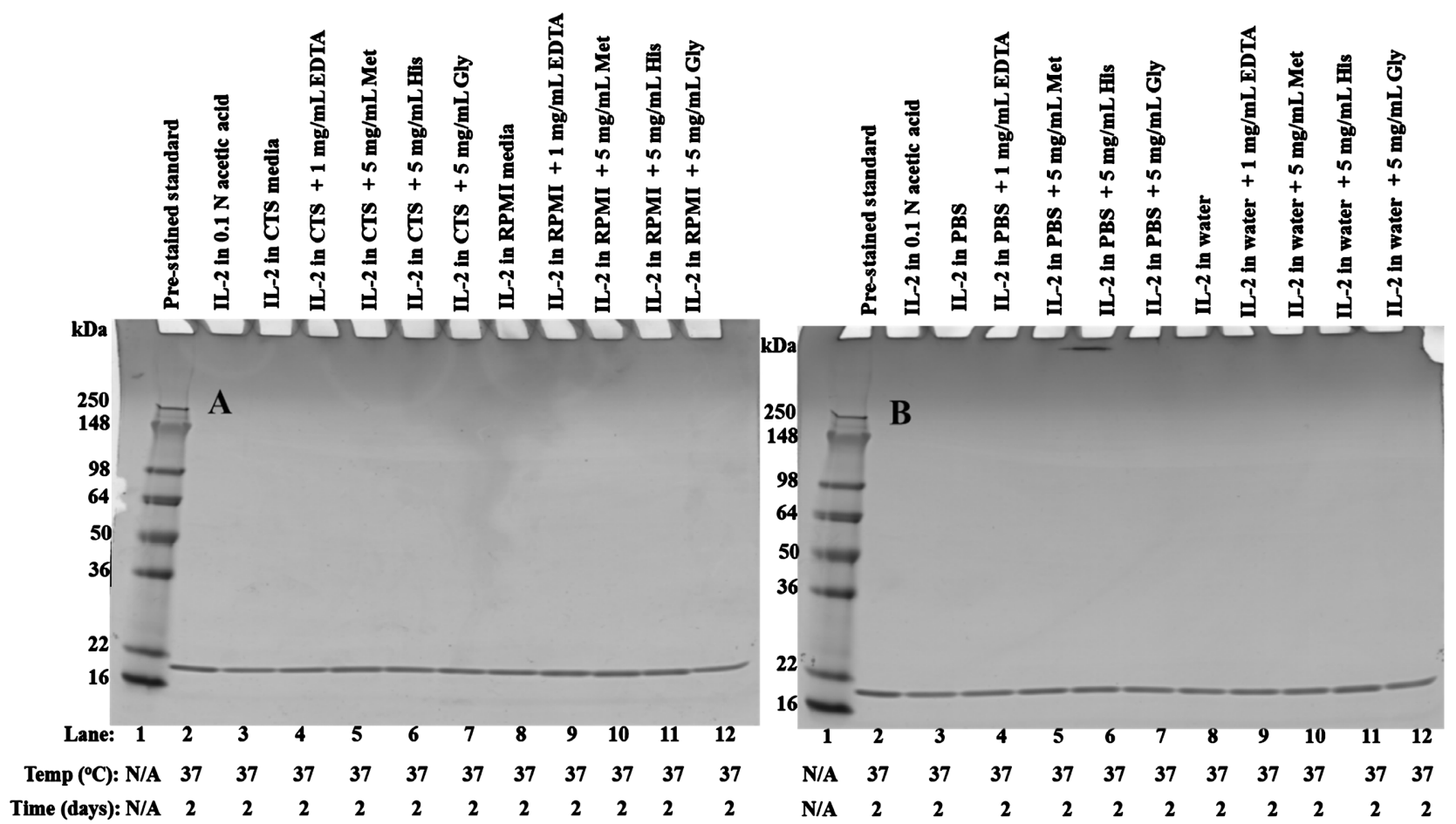

Figure S2. Effect of excipients on IL-2 stability in aqueous solutions after 2 days incubation at $37^{\circ} \mathrm{C}$. In separate vials, $1 \mu \mathrm{g}$ of IL-2 were prepared in (A) CTS and RPMI, (B) PBS and water in the presence of EDTA, Met, His and Gly. All vials were incubated for 2 days at $37^{\circ} \mathrm{C}$. The conformational stability was characterized by SDS-PAGE. 


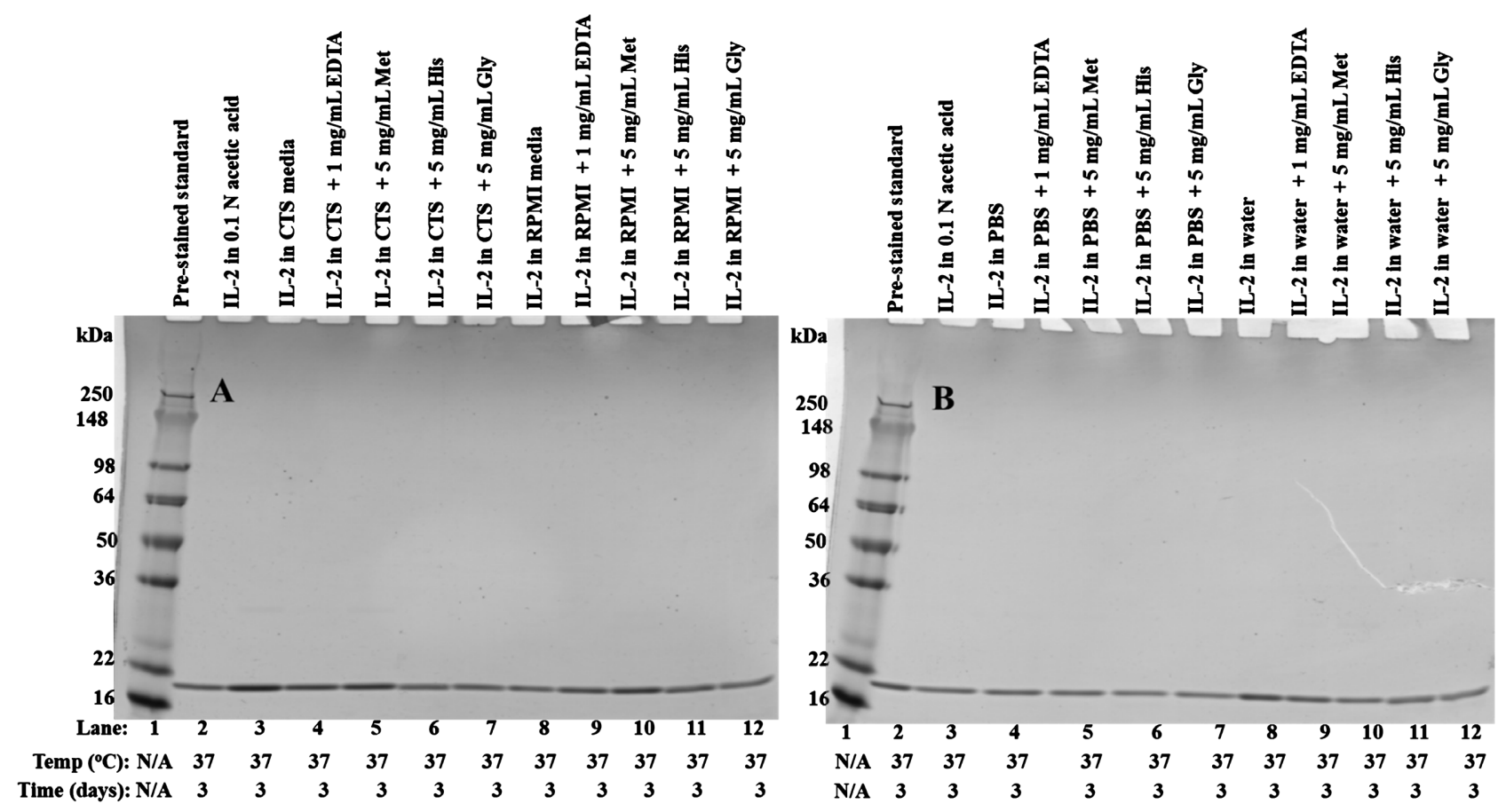

Figure S3. Effect of excipients on IL-2 stability in aqueous solutions after 3 day incubation at $37^{\circ} \mathrm{C}$. In separate vials, $1 \mu \mathrm{g}$ of IL-2 were prepared in (A) CTS and RPMI, (B) PBS and water in the presence of EDTA, Met, His and Gly. All vials were incubated for 3 days at $37^{\circ} \mathrm{C}$. The conformational stability was characterized by SDS-PAGE.

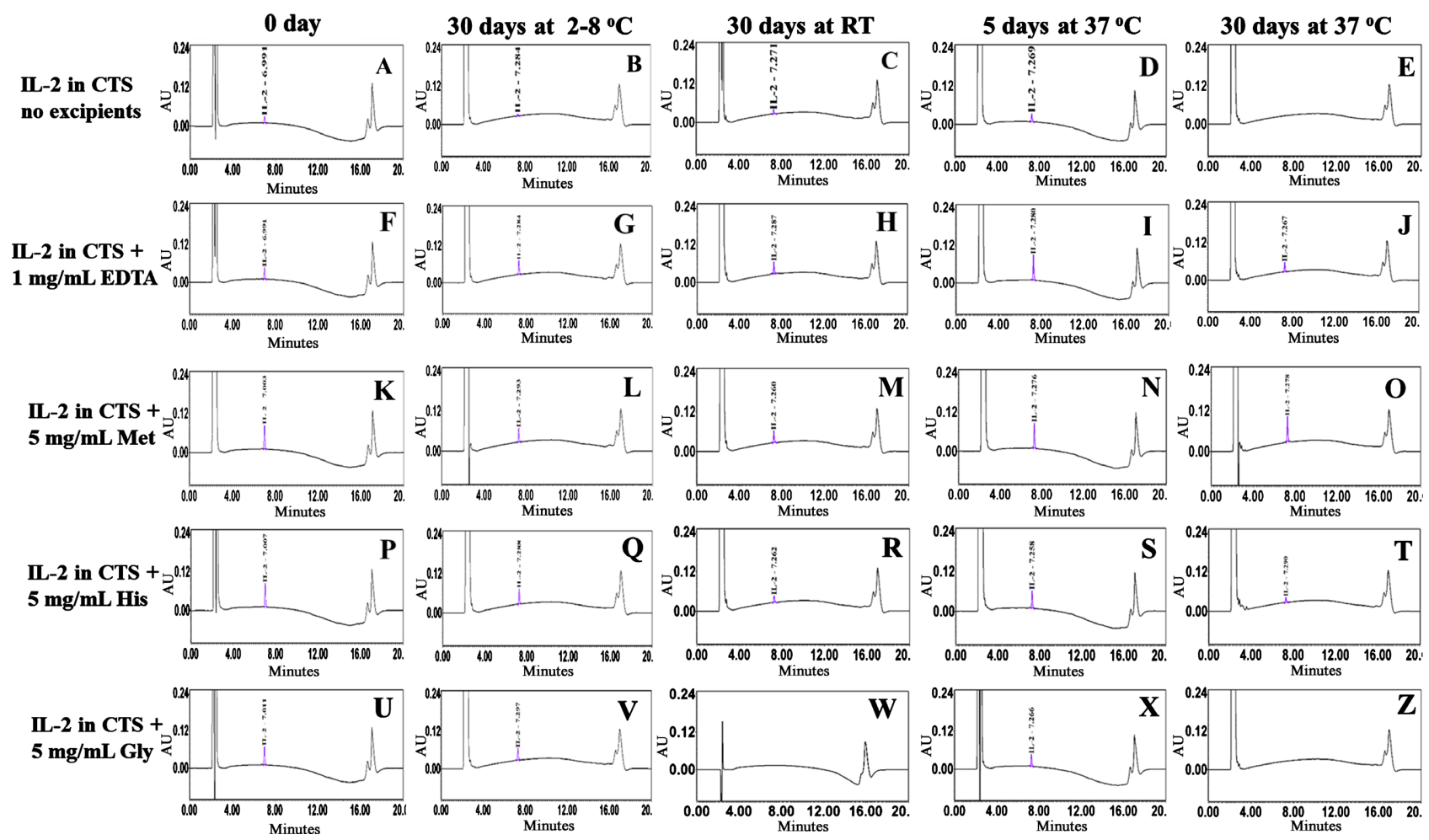

Figure S4. Effect of excipients on IL-2 stability in CTS at different temperatures. In separate glass vials, IL-2 was diluted to approximately $0.018 \mathrm{mg} / \mathrm{mL}$ in (A) CTS, Zero day (B) CTS for 30 days at $2^{\circ} \mathrm{C}-8^{\circ} \mathrm{C},(\mathrm{C})$ CTS for 30 days at $\left(20^{\circ} \mathrm{C} \pm 2^{\circ} \mathrm{C}\right.$ ), (D) CTS for 5 days at $37^{\circ} \mathrm{Cand}$ (E) CTS for 30 days at $37^{\circ} \mathrm{C}$. (F) CTS with EDTA, Zero day (G) CTS with EDTA for 30 days at $2^{\circ} \mathrm{C}-8^{\circ} \mathrm{C},(\mathrm{H})$ CTS with EDTA for 30 days at RT $\left(20^{\circ} \mathrm{C} \pm 2^{\circ} \mathrm{C}\right)$, (I) CTS with EDTA for 5 days at $37^{\circ}$ Cand (J) CTS with EDTA for 30 days at 
$37^{\circ} \mathrm{C}$. (K) CTS with Met, Zero day (L) CTS with Met for 30 days at $2^{\circ} \mathrm{C}-8^{\circ} \mathrm{C}$, (M) CTS with Met for 30 days at RT $\left(20^{\circ} \mathrm{C} \pm 2{ }^{\circ} \mathrm{C}\right)$, (N) CTS with Met for 5 days at $37^{\circ} \mathrm{C}$ and (O) CTS with Met for 30 days at $37^{\circ} \mathrm{C}$. (P) CTS with His, Zero day (Q) CTS with His for 30 days at $2^{\circ} \mathrm{C}-8^{\circ} \mathrm{C}$, (R) CTS with His for 30 days at RT $\left(20^{\circ} \mathrm{C} \pm 2^{\circ} \mathrm{C}\right)$, (S) CTS with His for 5 days at $37^{\circ} \mathrm{Cand}(\mathrm{T}) \mathrm{CTS}$ with His for 30 days at $37^{\circ} \mathrm{C}$. (U) CTS with Gly, Zero day (V) CTS with Gly for 30 days at $2^{\circ} \mathrm{C}-8^{\circ} \mathrm{C},(\mathrm{W})$ CTS with Gly for 30 days at RT $\left(20^{\circ} \mathrm{C} \pm 2^{\circ} \mathrm{C}\right)$, (X) CTS with Gly for 5 days at $37^{\circ} \mathrm{Cand}(\mathrm{Y}) \mathrm{CTS}$ with Gly for 30 days at $37^{\circ} \mathrm{C}$. Periodically the solutions were analyzed separately by RP-HPLC and the percent recovery of IL-2 was determined.
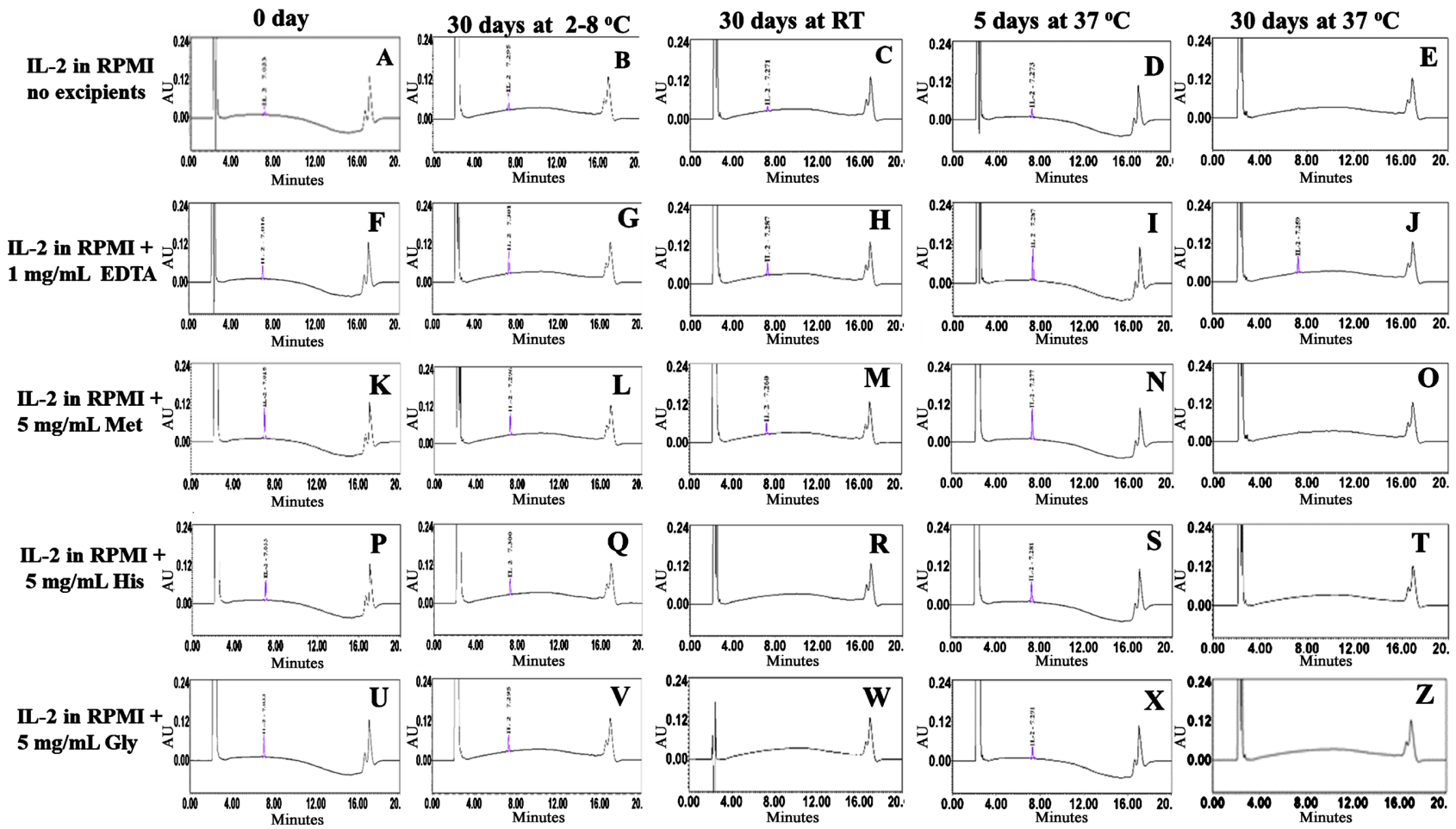

Figure S5. Effect of excipients onIL-2 stability in RPMI at different temperatures. In separate glass vials, IL-2 was diluted to approximately $0.018 \mathrm{mg} / \mathrm{mL}$ in (A) RPMI, Zero day, (B) RPMI for 30 days at $2^{\circ} \mathrm{C}-8^{\circ} \mathrm{C},(\mathrm{C}) \mathrm{RPMI}$ for 30 days at $\mathrm{RT}\left(20^{\circ} \mathrm{C} \pm 2{ }^{\circ} \mathrm{C}\right)$, (D) RPMI for 5 days at $37^{\circ}$ Cand (E) RPMI for 30 days at $37^{\circ} \mathrm{C}$. (F) RPMI with EDTA, Zero day (G) RPMI with EDTA for 30 days at $2^{\circ} \mathrm{C}-8{ }^{\circ} \mathrm{C}$, (H) RPMI with EDTA for 30 days at RT $\left(20^{\circ} \mathrm{C} \pm 2{ }^{\circ} \mathrm{C}\right)$, (I) RPMI with EDTA for 5 days at $37^{\circ} \mathrm{Cand}(\mathrm{J})$ RPMI with EDTA for 30 days at $37^{\circ} \mathrm{C}$. (K) RPMI with Met, Zero day (L) RPMI with Met for 30 days at $2^{\circ} \mathrm{C}-8^{\circ} \mathrm{C}$, (M) RPMI with Met for 30 days at RT $\left(20^{\circ} \mathrm{C} \pm 2{ }^{\circ} \mathrm{C}\right)$, (N) RPMI with Met for 5 days at $37^{\circ} \mathrm{Cand}(\mathrm{O}) \mathrm{RPMI}$ with Met for 30 days at $37^{\circ} \mathrm{C}$. (P) RPMI with His, Zero day (Q) RPMI with His for 30 days at $2^{\circ} \mathrm{C}-8^{\circ} \mathrm{C}$, (R) RPMI with His for 30 days at RT $\left(20^{\circ} \mathrm{C} \pm 2^{\circ} \mathrm{C}\right)$, (S) RPMI with His for 5 days at $37^{\circ} \mathrm{Cand}(\mathrm{T}) \mathrm{RPMI}$ with His for 30 days at $37^{\circ} \mathrm{C}$. (U) RPMI with Gly, Zero day (V) RPMI with Gly for 30 days at $2^{\circ} \mathrm{C}-8^{\circ} \mathrm{C}$, (W) RPMI with Gly for 30 days at RT $\left(20^{\circ} \mathrm{C} \pm 2{ }^{\circ} \mathrm{C}\right)$, (X) RPMI with Gly for 5 days at $37^{\circ} \mathrm{Cand}$ (Y) RPMI with Gly for 30 days at $37^{\circ} \mathrm{C}$. Periodically the solutions were analyzed separately by RP-HPLC and the percent recovery of IL- 2 was determined. 


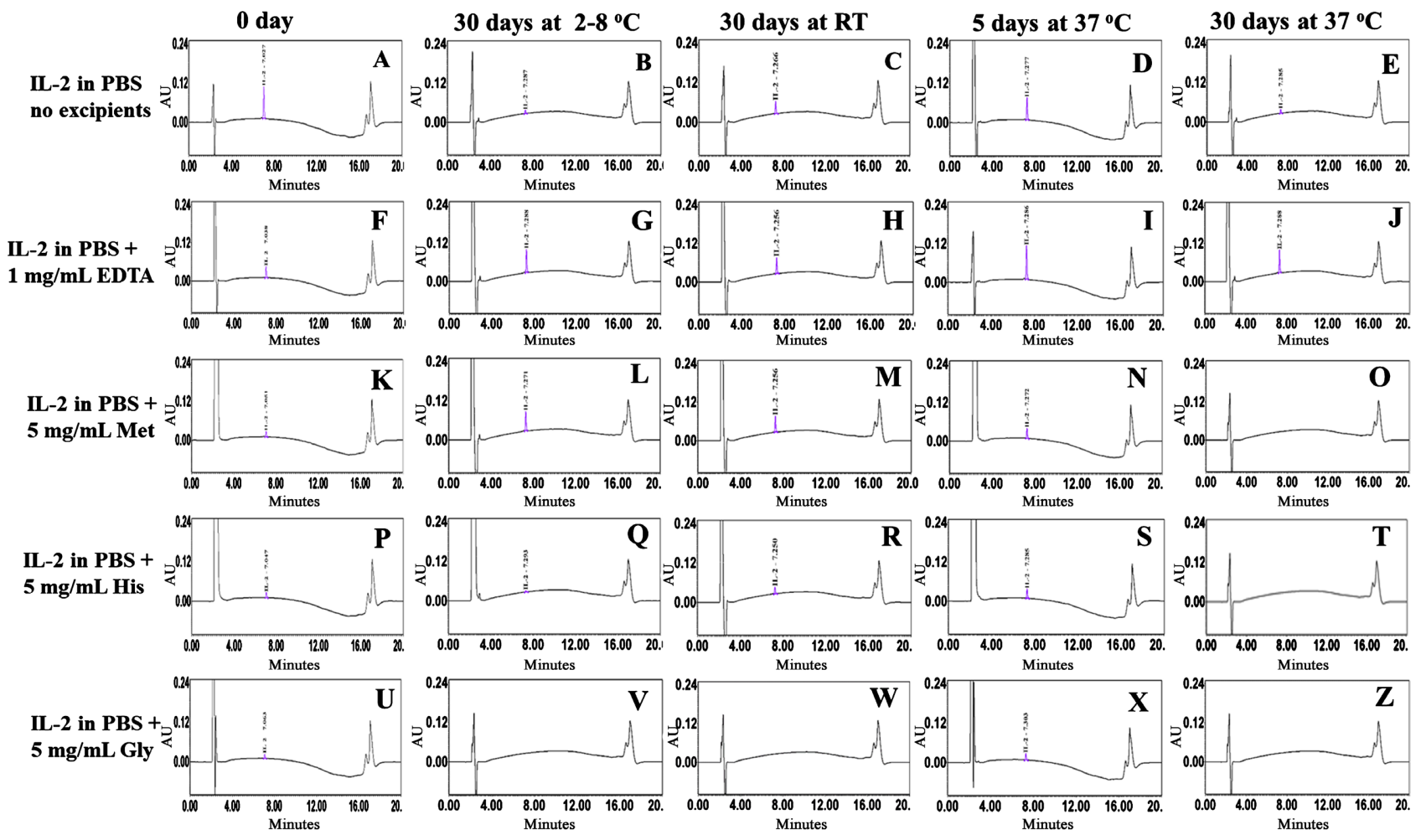

Figure S6. Effect of excipients onIL-2 stability in PBS at different temperatures. In separate glass vials, IL-2 was diluted to approximately $0.018 \mathrm{mg} / \mathrm{mL}$ in (A)PBS, Zero day (B) PBS for 30 days at $2^{\circ} \mathrm{C}-8^{\circ} \mathrm{C}$, (C) PBS for 30 days at $\mathrm{RT}\left(20^{\circ} \mathrm{C} \pm 2^{\circ} \mathrm{C}\right)$, (D) PBS for 5 days at $37^{\circ} \mathrm{Cand}$ (E) PBS for 30 days at $37^{\circ} \mathrm{C}$. (F) PBS with EDTA, Zero day (G) PBS with EDTA for 30 days at $2^{\circ} \mathrm{C}-8^{\circ} \mathrm{C},(\mathrm{H})$ PBS with EDTA for 30 days at RT $\left(20^{\circ} \mathrm{C} \pm 2^{\circ} \mathrm{C}\right)$, (I) PBS with EDTA for 5 days at $37^{\circ} \mathrm{Cand}$ (J) PBS with EDTA for 30 days at $37^{\circ} \mathrm{C}$. (K) PBS with Met, Zero day (L) PBS with Met for 30 days at $2^{\circ} \mathrm{C}-8^{\circ} \mathrm{C},(\mathrm{M}) \mathrm{PBS}$ with Met for 30 days at $\mathrm{RT}\left(20^{\circ} \mathrm{C} \pm 2^{\circ} \mathrm{C}\right)$, (N) $\mathrm{PBS}$ with Met for 5 days at $37^{\circ}$ Cand (O) PBS with Met for 30 days at $37^{\circ} \mathrm{C}$. (P) PBS with His, Zero day (Q) PBS with His for 30 days at $2^{\circ} \mathrm{C}-8^{\circ} \mathrm{C}$, (R) PBS with His for 30 days at RT $\left(20^{\circ} \mathrm{C} \pm 2^{\circ} \mathrm{C}\right)$, (S) PBS with His for 5 days at $37^{\circ}$ Cand (T) PBS with His for 30 days at $37^{\circ} \mathrm{C}$. (U) PBS with Gly, Zero day (V) PBS with Gly for 30 days at $2^{\circ} \mathrm{C}-8^{\circ} \mathrm{C}$, (W) PBS with Gly for 30 days at $\mathrm{RT}\left(20^{\circ} \mathrm{C} \pm 2{ }^{\circ} \mathrm{C}\right)$, (X) PBS with Gly for 5 days at $37^{\circ} \mathrm{Cand}(\mathrm{Y}) \mathrm{PBS}$ with Gly for 30 days at $37^{\circ} \mathrm{C}$. Periodically the solutions were analyzed separately by RP-HPLC and the percent recovery of IL-2 was determined. 


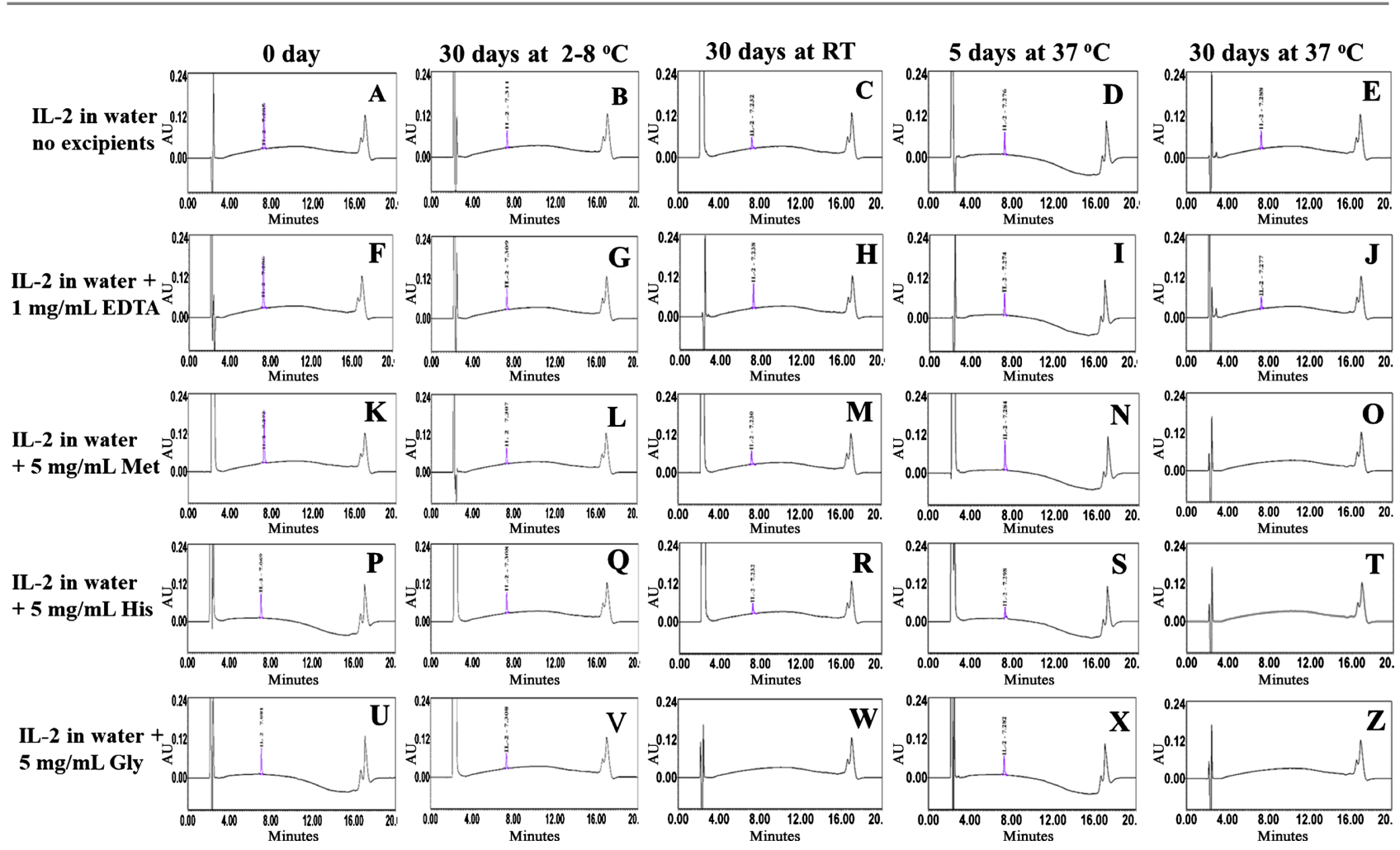

Figure S7. Effect of excipients onIL-2 stability in water at different temperatures. In separate glass vials, IL-2 was diluted to approximately $0.018 \mathrm{mg} / \mathrm{mL}$ in $(\mathrm{A})$ water, Zero day (B) water for 30 days at $2^{\circ} \mathrm{C}-8^{\circ} \mathrm{C},(\mathrm{C})$ water for 30 days at $\mathrm{RT}\left(20^{\circ} \mathrm{C} \pm 2^{\circ} \mathrm{C}\right),(\mathrm{D})$ water for 5 days at $37^{\circ} \mathrm{Cand}(\mathrm{E})$ water for 30 days at $37^{\circ} \mathrm{C}$. (F) water with EDTA, Zero day (G) water with EDTA for 30 days at $2^{\circ} \mathrm{C}$ $-8^{\circ} \mathrm{C},(\mathrm{H})$ water with EDTA for 30 days at RT $\left(20^{\circ} \mathrm{C} \pm 2^{\circ} \mathrm{C}\right)$, (I) water with EDTA for 5 days at $37^{\circ}$ Cand (J) water with EDTA for 30 days at $37^{\circ} \mathrm{C}$. $(\mathrm{K})$ water with Met, Zero day $(\mathrm{L})$ water with Met for 30 days at $2^{\circ} \mathrm{C}-8^{\circ} \mathrm{C}$, (M) water with Met for 30 days at RT $\left(20^{\circ} \mathrm{C} \pm 2{ }^{\circ} \mathrm{C}\right)$, (N) water with Met for 5 days at $37^{\circ} \mathrm{Cand}(\mathrm{O})$ water with Met for 30 days at $37^{\circ} \mathrm{C}$. (P) water with His, Zero day $(\mathrm{Q})$ water with His for 30 days at $2^{\circ} \mathrm{C}-8^{\circ} \mathrm{C}$, (R) water with His for 30 days at $\mathrm{RT}\left(20^{\circ} \mathrm{C} \pm 2^{\circ} \mathrm{C}\right)$, (S) water with His for 5 days at $37^{\circ} \mathrm{C}$ and (T) water with His for 30 days at $37^{\circ} \mathrm{C}$. (U) water with Gly, Zero day (V) water with Gly for 30 days at $2^{\circ} \mathrm{C}-8^{\circ} \mathrm{C}$, (W) water with Gly for 30 days at RT $\left(20^{\circ} \mathrm{C} \pm 2^{\circ} \mathrm{C}\right)$, (X) water with Gly for 5 days at $37^{\circ} \mathrm{Cand}(\mathrm{Y})$ water with Gly for 30 days at $37^{\circ} \mathrm{C}$. Periodically the solutions were analyzed separately by RP-HPLC and the percent recovery of IL-2 was determined. 